Portland State University

PDXScholar

Spring 7-19-2018

\title{
Intrapersonal and Social-Contextual Factors Related to Psychological Well-being among Youth Experiencing Homelessness
}

Katricia Stewart

Portland State University

Follow this and additional works at: https://pdxscholar.library.pdx.edu/open_access_etds

Part of the Psychology Commons

Let us know how access to this document benefits you.

Recommended Citation

Stewart, Katricia, "Intrapersonal and Social-Contextual Factors Related to Psychological Well-being among Youth Experiencing Homelessness" (2018). Dissertations and Theses. Paper 4443.

https://doi.org/10.15760/etd.6327

This Thesis is brought to you for free and open access. It has been accepted for inclusion in Dissertations and Theses by an authorized administrator of PDXScholar. Please contact us if we can make this document more accessible: pdxscholar@pdx.edu. 
Intrapersonal and Social-Contextual Factors Related to

Psychological Well-being among Youth Experiencing Homelessness

by

Katricia Stewart

A thesis proposal submitted in partial fulfillment of the requirements for the degree of

\author{
Master of Science \\ in \\ Applied Psychology
}

Thesis committee:

Greg Townley, Chair

Eric Mankowski

Keith Kaufman

\title{
Portland State University 2018
}


(C) 2018 Katricia Stewart 


\begin{abstract}
Homeless youth are typically defined as a group of adolescents and young adults (ages 12-24) who do not have stable dwellings, but instead live on the streets, in shelters or abandoned buildings, or in other unstable situations (e.g., doubling up with friends). Given the myriad of hardships, stressors, and marginalization faced by youth as they navigate life on the streets, it is encouraging that researchers have begun examining wellbeing among youth experiencing homelessness. However, the few studies examining well-being among homeless youth have produced inconsistent results. Furthermore, little is known about the components of well-being that are both relevant to and valued by homeless youth, as well as which factors predict differences in well-being among youth. This study examined psychological well-being and its associations with demographic characteristics (race, gender, and sexual orientation), intrapersonal factors (mental health, optimism, and self-esteem), and social-contextual factors (social support, sense of community, and empowerment) among 100 homeless youth utilizing services in Portland, Oregon. Quantitative results indicated that the intrapersonal and social-contextual variables were all significantly associated with psychological well-being among homeless youth at the bivariate level. However, in a full hierarchical regression model containing all study variables, only self-esteem and psychological distress were significant predictors of well-being. Thematic analysis of qualitative data revealed 11 categories of factors that impact youth's well-being, including Self Care, Social Support, and Personal Outlook. Collectively, findings have practical implications for program development at homeless youth service centers while also informing future research in this area.
\end{abstract}




\section{Acknowledgements}

I would like to express my gratitude for the numerous individuals and organizations who made this research possible. First, thank you to my advisor and committee chair, Greg Townley, for the guidance and support he provided throughout the entire project. His assistance was invaluable from the very beginning and at every step of the process, and I am deeply grateful for the abundance of wisdom, encouragement, and support he provided. Second, thank you to the other members of my thesis committee, Eric Mankowski and Keith Kaufman, for the support, feedback, and diverse perspectives they provided in shaping this project to be its best.

I would also like to thank the Society for Community Research and Action for awarding me the NSR thesis grant, which provided the needed funds for recruiting research participants. Further, a whole hearted thank you to p:ear, the non-profit youth mentoring center where data was collected. Their generous collaboration and support of their staff made this project possible. I would also like to extend deep gratitude to each and every youth who participated in this project, for their vulnerability, openness, and willingness to share themselves with a stranger. I truly hope that this research can make a positive difference in their lives and the lives of future youth experiencing adversity.

Finally, thank you to the numerous members of my community and family (Ellie, Dave, Sara, Otis, my partner Kurt, and my mother Lacy) who have supported me in my education thus far, and who both inspired and encouraged me to conduct this research. 
Table of Contents

Title

Page

Abstract

Acknowledgements

List of Tables

List of Figures

Introduction

Factors Contributing to Youth Homelessness

Familial Breakdown

Academic Achievement

Brain Development

Mental Illness and Substance Use

Well-Being

Psychological Well-Being $\quad 12$

Subjective Well-Being 14

Relationship Between Psychological and Subjective Well-Being 15

$\begin{array}{ll}\text { Intrapersonal Factors Related to Well-Being } & 17\end{array}$

$\begin{array}{ll}\text { Mental Health } & 17\end{array}$

$\begin{array}{ll}\text { Optimism } & 18\end{array}$

Self-esteem 20

Social-Contextual Factors Related to Well-Being 22

Sense of Community 22

Social Support $\quad 24$

Empowerment 26

Problem Statement 28

Study Purpose, Research Questions, and Hypotheses 29

Methods $\quad 34$

Participants $\quad 34$

Demographics and Participant Characteristics 34

Measures

35

Psychological Well-Being $\quad 35$

Mental Health $\quad 36$

Optimism $\quad 36$

Self-esteem $\quad 36$

Sense of Community 37

Social Support $\quad 37$

Empowerment 38

Qualitative Reports of Factors Influencing Well-Being 38

Design and Procedures 39

Results $\quad 41$

Data Preparation, Screening and Preliminary Analyses 41

Quantitative Data Analyses and Results $\quad 42$

Qualitative Data Analyses and Results 47

Discussion

50 
WELL-BEING AMONG HOMELESS YOUTH iv

Study Findings and Implications $\quad 50$

Demographics and Participant Characteristics $\quad 50$

Intrapersonal Predictors of Psychological Well-Being 52

Social-Contextual Predictors of Psychological Well-Being 55

Hierarchical Regression Predicting Psychological Well-Being 58

$\begin{array}{ll}\text { Open-Ended Well-Being Responses } & 60\end{array}$

Limitations $\quad 62$

Future Directions $\quad 66$

Conclusion

69

Tables and Figures $\quad 70$

$\begin{array}{ll}\text { References } & 78\end{array}$

$\begin{array}{ll}\text { Appendix } & 104\end{array}$

$\begin{array}{ll}\text { Measures } & 104\end{array}$ 
List of Tables

Table 1. Descriptive Statistics $\quad 70$

Table 2. Demographic Percentages $\quad 71$

Table 3. Correlation Matrix of Variables $\quad 72$

Table 4. Linear Regression of Intrapersonal

Variables Predicting Psychological Well-Being 73

Table 5. Linear Regression of Social-Contextual

Variables Predicting Psychological Well-Being 74

Table 6. Hierarchical Regression of Intrapersonal and Social-

Contextual Variables Predicting Psychological Well-Being 75

Table 7. Thematic Categories for the Open-Ended Well-Being Question 76 
List of Figures

Figure 1. Well-Being Predicted by Intrapersonal and Social-Contextual Factors 


\author{
Intrapersonal and Social-Contextual Factors Related to \\ Psychological Well-being among Youth Experiencing Homelessness \\ Introduction
}

Homeless youth are typically defined as a group of unaccompanied adolescents and young adults (ages 12-24) who do not have stable dwellings, but instead live on the streets, in shelters or abandoned buildings, or in other unstable situations (e.g., doubling up with friends) (Kidd \& Davidson, 2009). The National Alliance to End Homelessness (NAEH) estimates that over the course of one year, approximately 550,000 unaccompanied, single youth and young adults experience a homelessness episode of longer than one week (NAEH Youth, 2014).

Previously studied factors that contribute to youth homelessness exist primarily between the individual and microsystem levels of analysis (Bronfenbrenner, 1979), specifically between youth and their families. However, numerous other organizational and institutional structures and processes may prolong homelessness, while also influencing the family-youth interactions that contributed to initial homelessness.

For example, in a study of 302 homeless youth in Australia, all participants described familial conflict or breakdown as a reason for homelessness or leaving home (Mallett, Rosenthal, \& Keyes, 2005). One-fifth of the participants indicated their own alcohol and/or drug use as contributing to the conflict, while $26 \%$ cited the alcohol or drug use of other family members as contributing to familial conflict (Mallett, Rosenthal, \& Keyes, 2005). Moreover, youth described two ways that drug and/or alcohol use among either themselves or a family member played a role in their subsequent 
homelessness: 1) that drug and/or alcohol use contributed to shifts in family dynamics that then led to their homelessness; or 2) that family conflict contributed to their drug use as a way to cope with this stressor, which then led to them leaving home (Mallett, Rosenthal, \& Keyes, 2005). However, other youth in this study described familial conflict as a direct cause of their homelessness, with drug and/or alcohol use beginning after they were already homeless (Mallett, Rosenthal, \& Keyes, 2005). Although drug and alcohol use among youth and their family members represents just one of the many factors that contribute to youth homelessness, this example illustrates the complex interactions between youth and their families that may influence homelessness.

Once homeless, youth face many barriers to transitioning back into housing, such as risk factors involved with living on the streets (e.g., violence and abuse) (Coates \& McKenzie-Mohr, 2010), or pressures from peers to engage in substance use (Mallett, Rosenthal, \& Keyes, 2005). However, they also face structural hurdles that aggravate homelessness, such as financial barriers to accessing healthcare (Christiani, Hudson, Nyamathi, Mutere, \& Sweat, 2008) and difficulties in accessing free or affordable housing and education (National Health Care for the Homeless Council, 2008).

Moreover, the stressors faced by homeless youth both prior to and during homelessness contribute to abnormally high rates of mental illness among members of this population (Kamieniecki, 2001; Moore, 2005; Slesnick \& Prestopnik, 2005), as well as markedly high rates of suicidal ideation and attempted and completed suicide (Desai, Liu-Mares, Dausey, \& Rosenheck, 2003; Kamieniecki, 2001). This interaction between risk factors and mental illness, as well as the structural barriers noted above, has the 
potential to obstruct youth's capacity to transition out of homelessness and street culture.

Although the risk factors and struggles faced by many homeless youth may paint a bleak picture for their projected outcomes, some research suggests that homeless youth may be quite resilient in the face of this adversity, capitalizing on both internal and external resources to survive on the streets (Cleverley \& Kidd, 2011; Kidd \& Carroll, 2007; Kidd \& Shahar, 2008). Utilization of these resources may be a key component to maintaining one's well-being while homeless. However, studies examining the wellbeing of homeless youth have been inconsistent, measuring well-being in a myriad of ways and with inconsistent findings (Barczyk, Thompson, \& Rew, 2014; Taylor, Lyndon, Bougie, \& Johannsen, 2004; Usborne, Lyndon, \& Taylor, 2009). This may be due in part to selecting measures of "well-being" that may not accurately capture the full meaning of the construct (e.g., measures focusing on psychological symptom distress rather than positive psychological functioning), but also potentially due to the well-being constructs and measures lacking relevance to the values and experiences of homeless youth.

The present study aims to develop a deeper and more specific understanding of the well-being of youth experiencing homelessness, particularly the intrapersonal and social-contextual factors that may predict greater levels of psychological well-being among some members of this population. Considering the substantial overlap between correlates of well-being and protective factors associated with resilience, examining the nature of well-being among homeless youth may be critical to understanding how youth are able to overcome the stressors of street life, as well as what can be done to bolster their chances of experiencing positive outcomes despite the challenges they may face. 


\section{Factors Contributing to Youth Homelessness}

Before reviewing the primary constructs that will be examined in this study, it is first important to discuss some of the major factors that contribute to youth homelessness, including familial breakdown, hindered academic achievement and brain development, and psychiatric distress. Many of these precursors also compound the challenges that youth face once they are on the streets, further complicating their efforts to transition out of homelessness.

\section{Familial Breakdown}

The social context influencing youth homelessness often centers around familial breakdown or disruptive family relationships, including behaviors of parents, economic problems, and residential instability (Reeg, 2003; van Wormer, 2003). In one sample, most of the homeless youth reported one or more adverse childhood experiences, and nearly half reported four or more, which is the cut-off associated with an increased risk of poor mental health and behavioral outcomes (Felitti et al., 1998; Kozloff et al., 2016).

Research has suggested a bidirectional relationship between homelessness and abuse: youth may leave home to avoid abuse but unfortunately encounter further abuse while homeless (Coates \& McKenzie-Mohr, 2010). More specifically, homeless youth report experiencing high rates of trauma and abuse both prior to and during homelessness (Coates \& McKenzie-Mohr, 2010), including abusive family relationships associated with subsequent mental health problems (Haber \& Toro, 2009). The violence and trauma that youth experience while homeless puts them at a greater risk of psychological consequences than their housed counterparts, including higher rates of anxiety and 
depressive symptoms, anger, and irritability (Coates \& McKenzie-Mohr, 2010).

Gay, lesbian, and transgender youth are often at a greater disadvantage, and their narratives are filled with reports of abuse and being forced to leave home after revealing their sexual orientation and/or gender identity to their families (Kidd \& Kral, 2002). Youth who identify as LGBTQ are 4 to $13 \%$ more likely to experience homelessness than heterosexual youth; and some surveys have reported that as high as $40 \%$ of service-using youth identify as LGBTQ (Durso \& Gates, 2012). Homeless LGBTQ youth have been found to engage in riskier survival strategies and are victimized more frequently than non-LGBTQ homeless youth (Whitbeck et al., 2004). These challenges and the resulting marginalization are compounded among homeless LGBTQ youth of color (Reck, 2009).

The history of trauma and abuse that many homeless youth experience combined with unstable or dangerous living situations, limited emotional and financial resources, engagement in substance abuse and high-risk activity, and irregular sleeping and eating patterns - all contribute to poorer physical and mental health among homeless youth as compared to housed youth (Johnson et al., 1996; Robertson \& Toro, 1999; Salomonsen-Sautel et al., 2008; Wrate \& McLoughlin, 1997).

\section{Academic Achievement}

Many young people are supported by their families well into their 20's, providing resources and opportunities that enable many youth to successfully transition into adulthood (U.S. Census Bureau, 2009). Homeless youth do not have this advantage (Cohen, Kasen, Chen, Hartmark, \& Gordon, 2003) and may find themselves ill-equipped to transition smoothly into societal standards of adulthood. Although familial breakdown 
represents one of the primary factors contributing to youth homelessness, familial breakdown and subsequent homelessness are further associated with reduced academic achievement among homeless youth (Buckner, Bassuck, \& Weinreb, 2001), which can create a downward spiral of negative consequences for this marginalized population.

The multitude of stressful events experienced by homeless youth are associated with learning difficulties (Bryk, Sebrig, Allensworth, Luppesca, \& Easton, 2010) and lower levels of academic achievement (Buckner, Bassuk, \& Weinreb, 2001; Fantuzzo \& Perlman, 2007; Obradovic et al., 2009; Rafferty, Shinn, \& Weitzman, 2004; Rubin et al., 1996). Low levels of academic achievement can make it more difficult for youth to obtain employment, access housing, and transition out of homelessness (Buckner, Bassuk, \& Weinreb, 2001; Fantuzzo \& Perlman, 2007; Obradovic et al., 2009; Rafferty, Shinn, \& Weitzman, 2004; Rubin et al., 1996; Zima, Wells, \& Freeman, 1994).

If they are able to gain employment, homeless youth are more likely to work in lower paying jobs without benefits or health insurance, and with limited opportunities to save money (National Health Care for the Homeless Council, 2008). They are also less likely to know of community resources for assistance, as well as their legal and housing rights. Further, once they are 18, youth are often unable to access free or affordable education (National Health Care for the Homeless Council, 2008), which can impede efforts to gain education for employment purposes and further complicate the employment barriers they face. These factors can exacerbate the stressors of homelessness and extend periods of time spent on the streets (Edidin, Ganim, Hunder, \& Karnik, 2012). 


\section{Brain Development}

In addition to lower levels of academic achievement and its associated consequences, the stressors faced by homeless youth can also have a negative influence on brain development. Research has demonstrated that stress increases the speed at which the prefrontal cortex develops, which prematurely stunts neural growth. This can have a permanent negative effect on cognitive functioning in children (Teicher et al., 2003). When specifically studied among homeless youth, the effects of this stress on the prefrontal cortex can include deficits in visuomotor and problem solving skills, processing speed, verbal ability, judgment, logical thinking, and self-regulation (Parks, Stevens, \& Spence, 2007; Yu, North, LaVesser, Osborne, \& Spitznagel, 2008).

Of distinct concern is hindered self-regulatory development among homeless youth. Self-regulation processes include strategy identification, decision making, inhibition, reasoning, working memory, planning, organization, and behavior and emotion regulation (Blakemore \& Choudhury, 2006; Giedd, 2008; Hackman \& Farah, 2008; Noble, McCandliss, \& Farah, 2007), all of which aid in coping with stressors. Typically, supportive adults assist adolescents in the development of decision-making, reasoning skills, and learning effective coping strategies. Compared to housed youth, youth who experience homelessness are less likely to have supportive adults in their lives, especially considering the extent to which familial conflict and lack of familiar support contributes to youth homelessness (Haber \& Toro, 2009). Moreover, unaccompanied homeless youth are, by definition, not living with their families or other supportive adults, and their self-regulatory development may therefore be impaired. 
This interplay between familial breakdown and hindered academic and brain development can both contribute to initial homelessness and also increase the barriers to transitioning out of homelessness. Unfortunately, these risk factors and other stressors further contribute to relatively high rates of mental illness among homeless youth.

\section{Mental Illness and Substance Use}

Although mental illness can and sometimes does precede homelessness, the detrimental effects of homelessness on mental health are consistently noted in research (Castellow, Kloos, \& Townley, 2015). Familial breakdown, abuse, trauma, reduced selfregulatory processes, and concurrent stressors are all likely contributors to the high rates of mental illness among this population, while homelessness itself has both short- and long-term effects on mental health. However, it can be difficult to determine whether the mental health status of homeless youth was caused by pre-existing mental illness, chronic stress, the demands of homelessness, substance use, or a combination of these factors (Robertson, 1996). Nevertheless, the burden of mental illness on homeless youth contributes to an 11-times increased mortality rate, accounted for primarily by suicide and drug overdose (Roy et al., 2004), while lifetime rates of depressive disorders, PTSD, and alcohol and drug abuse are many times higher among homeless youth than housed adolescents (Whitbeck, Hoyt, Johnson, \& Chen, 2007).

More specifically, homeless youth experience high rates of psychiatric disorders compared to peers of the same age group (Kessler, Berglund, Demler, et al., 2005); and LGBTQ youth have poorer mental health relative to heterosexual homeless youth (Whitbeck et al., 2004). Multiple studies have demonstrated that 48 to $98 \%$ of homeless 
youth meet the criteria for a psychiatric disorder (Hodgson, Shelton, van den Bree, et al., 2013). A recent study by Kozloff and colleagues (2016) conducted across five cities in Canada delineated the rates of different mental illnesses among homeless youth, including major depressive episodes (51\%); manic or hypomanic episodes (21\%); PTSD (35\%); psychotic disorder (29\%); substance use disorder (74\%); and moderate or higher suicidality (41\%). Furthermore, over $40 \%$ of these youth reported two or more psychiatric hospitalizations within the previous five years (Kozloff et al., 2016).

While rates of mental and emotional distress are disproportionately high among homeless youth, they also have numerous barriers to accessing mental-emotional support. High rates of homeless youth (50\%) report a perceived unmet need for health care in the past six months (Kozloff et al., 2016). Some barriers to accessing health care that homeless youth cite include financial, structural, or personal barriers; fear of encountering discrimination and negative judgments; and prioritization of certain health conditions which results in a lack of services for individuals who do not have these conditions (Christiani, Hudson, Nyamathi, Mutere, \& Sweat, 2008; Hudson et al., 2010; Reid, Berman, \& Forchuk, 2005). These barriers to formal social support, as well as the length of the homeless episode, contribute to psychological distress among homeless youth (Cleverley \& Kidd, 2010; Wrate \& Blair, 1999).

Of important consideration are the high reported rates of substance abuse among homeless youth, as substance abuse is associated with higher levels of psychological distress (Kidd \& Carroll, 2007; Romer et al., 2009). Homeless youth are more likely than homeless adults to have drug use disorders and more likely than housed youth to use 
substances in general (Kessler, et al., 2005). Further, those who use substances are more likely to experience negative mental health consequences, such as depression and anxiety (Black, Serowik, \& Rosen, 2009; Fischer \& Breakey, 1991; Nyamathi et al., 2010). The challenges of homelessness and barriers to care that youth face are further exacerbated for homeless youth with co-occurring mental illness and substance use disorders (Kozloff et al., 2013).

Of the specific experiences of homelessness that contribute to the disparities in mental health between homeless youth and their housed counterparts, loneliness and feeling trapped are two key elements. Homeless youth describe feeling alienated from society, estrangement from family, and unreliable social support - all of which contribute to high reports of loneliness among this population (Kidd, 2003). Further, feeling trapped is a central component of emotional distress among this group, with "trapped" referring to times when youth feel unable to cope effectively with the personal, contextual, and structural stressors they face (Kidd, 2003).

History of familial breakdown, combined with unstable or dangerous living situations, limited emotional resources, and engagement in substance abuse and high-risk activity, all contribute to the higher likelihood that unaccompanied homeless youth experience interferences in development, achievement, self-regulation, and mental health (Johnson, Aschkenasy, Herbers, \& Gillenwater, 1996; Robertson \& Toro, 1999; Salomonsen-Sautel et al., 2008; Wrate \& McLoughlin, 1997). Barriers to accessing services and increased time spent homeless further complicate psychiatric distress. Although these risk factors can contribute to a vicious cycle of homelessness and 
drastically impact the welfare and well-being of this population, research has demonstrated characteristics of well-being and resilience among this population that may protect homeless youth and bolster their chances of achieving positive outcomes in the face of adversity.

\section{Well-Being}

Because of the high levels of marginalization, mental health distress, and hardships faced by many homeless youth, lower levels of well-being would be expected among members of this population. Surprisingly, one of the few studies examining the well-being of homeless youth found that many youth report their well-being similarly to that of their housed peers (Taylor et al., 2004). However, previous research with homeless youth has been highly varied in how researchers chose to measure well-being, often opting for a combination of measures that may suggest well-being, but that do not directly and holistically capture the construct (Barczyk, Thompson, \& Rew, 2014; Usborne, Lyndon, \& Taylor, 2009). The few studies that have utilized established measures of well-being in research with homeless youth have reported varied levels of well-being among youth (Taylor et al., 2004; Townley, Pearson, Lehrwyn, Prophet, \& Trauernicht, 2016). These inconsistencies point to the need for further examination of well-being, with a particular focus on factors that may explain discrepancies in wellbeing among youth experiencing homelessness. Currently, the literature suggests two primary ways that well-being is conceptualized, Psychological Well-Being and Subjective Well-Being, which will be reviewed briefly before turning to a discussion of factors that may influence well-being among homeless youth. 


\section{Psychological Well-Being}

Psychological Well-Being (PWB) is a multidimensional model of well-being that encompasses six distinct components of positive psychological functioning: selfacceptance, positive relations with others, autonomy, mastery of the surrounding environment, purpose in life, and personal growth and development (Ryff, 1989; 1995). These components of psychological well-being are distinct but conceptually overlapping. This model of PWB is assessed with a survey measure that can vary in item-length depending upon the purposes of the research. High and low scores on the six components of PWB measured in this survey are defined as follows (Ryff \& Keyes, 1995):

Self-Acceptance: Those with high scores have a positive attitude toward the self; acknowledge and accept multiple aspects of the self, including good and bad qualities; and feel positive about previous life experiences. Lower scores indicate a feeling of dissatisfaction with oneself, disappointment with what has occurred in the past, feeling troubled about certain personal qualities, and wishing to be different than who one is.

Positive Relations with Others: High scorers tend to have warm, satisfying, trusting relationships with others; are concerned about the welfare of others; are capable of strong empathy, affection, and intimacy; and understand the give and take of human relationships. Those with lower scores tend to have few close, trusting relationships with others; find it difficult to be warm, open, and concerned about others; are isolated and frustrated in interpersonal relationships; and are not willing to make compromises to sustain important ties with others.

Autonomy: Those scoring higher tend to be self-determining and independent; are 
able to resist social pressures to think and act in certain ways; regulate behavior from within; and evaluate the self by personal standards. Those scoring lower tend to be concerned about the expectations and evaluations of others; rely on judgments of others to make important decisions; and conform to social pressures to think and act in certain ways.

Environmental Mastery: High scorers have a sense of mastery and competence in managing the environment; are able to control a complex array of external activities; make effective use of surrounding opportunities; and are able to choose or create contexts suitable to personal needs and values. Low scorers have difficulty managing everyday affairs; feel unable to change or improve their surrounding context; are unaware of surrounding opportunities; and lack a sense of control over the external world.

Purpose in Life: Those with high scores tend to have goals in life and a sense of directedness; feel a sense of meaning toward the present and their past; hold beliefs that give life purpose; and have aims and objectives for living. Low scorers tend to lack a sense of meaning in life; have few goals or aims and lack a sense of direction; do not see purpose in one's past; and have no outlooks or beliefs that give life meaning.

Personal Growth: High scorers have a feeling of continued development; see oneself as growing and expanding; are open to new experiences; have a sense of realizing one's potential; see improvement in oneself and one's own behavior over time; and tend to change in ways that reflect more self-knowledge and effectiveness. Low scorers tend to have a sense of personal stagnation; lack a sense of improvement or expansion over time; feel bored and uninterested with life; and often feel unable to develop new attitudes 
or behaviors.

Studies of psychological well-being across the lifespan have found that environmental mastery and autonomy tend to increase with age; purpose in life and personal growth tend to decrease with age; and self-acceptance and positive relations tend to vary or stay the same across the lifespan. Research has also shown that women tend to score higher than men on positive relations with others (Ryff \& Keyes, 1995).

\section{Subjective Well-Being}

Subjective Well-Being (SWB) is a global assessment of one's life and consists of three primary components: global life satisfaction judgements, positive emotional affect, and negative emotional affect. A fourth component, domain satisfaction, can also be examined to gain a fuller picture of how subjective well-being may vary within different areas of life, such as marriage, work, and health (Diener, Scollon, \& Lucas, 2009). These four components are moderately correlated and conceptually related, but each provides unique information regarding the subjective quality of an individual's life.

The subjective nature of well-being drives the theory behind SWB. Humans are capable of continually appraising the events of their own lives and life circumstances. Indeed, the appraisal of events in terms of goodness and badness is universal. Appraisal leads to emotional reactions that can be either pleasant or unpleasant. With all other factors being equal, pleasant experiences are typically seen as valuable and desirable (Diener, 2009). Therefore, a person with pleasant emotional experiences is more likely to perceive life as being desirable and positive. Said another way, subjective well-being resides within the individual's appraisal of his or her own experience (Diener, 2009). 
People who are high in SWB make positive appraisals of their life events and circumstances; have higher levels of positive affect and a general lack of unpleasant affect over time; and report higher levels of life satisfaction (Diener, 2009).

\section{Relationship between Psychological and Subjective Well-Being}

Measures of subjective well-being (SWB) and psychological well-being (PWB) have been shown to be significantly correlated (Keyes, Shmotkin, \& Ryff, 2002). For example, in a study utilizing hierarchical regression and controlling for personality variables, PWB was a significant predictor of SWB (Burns \& Machin, 2010). However, the two conceptualizations of well-being are structured, defined, and measured from differing perspectives. Studies focusing on subjective well-being assess individuals' cognitive and affective appraisals of their lives. This tradition is typically categorized as hedonic research, focusing on happiness and suggesting that well-being is fundamentally about maximizing pleasure and avoiding or minimizing pain (Deci \& Ryan, 2008). However, some researchers argue that well-being is comprised of much more than happiness, and that happiness alone does not entail psychological wellness. Psychological well-being is, therefore, often used as a measure of psychological wellness, focusing on actualizing one's human potential and living well (Deci \& Ryan, 2008). Psychological well-being is meant to assess components of social-psychological wellness in the general context of one's life, making it a more holistic representation of well-being than subjective well-being.

Further, researchers have argued that SWB may be a poor indicator of long-term wellness if measured at only one time point. In particular, the emphasis on cognitive 
appraisal required in SWB is naturally based upon what an individual chooses as a standard of comparison. Individuals reporting SWB are more likely to use information that is salient at the time of judgement, while in reality positive and negative affect vary widely from day to day (Burns \& Machin, 2010). Thus, obtaining valid measurements of SWB likely requires measuring participants at multiple time points.

Considering that subjective well-being requires an individual to make comparisons to normative standards (Diener, 2009), perhaps homeless youth report higher than expected levels of subjective well-being (Barczyk, Thompson, \& Rew, 2014; Usborne, Lydon, \& Taylor, 2009) because they do not make comparisons with the typical societal standards that their housed peers may, or because the items used to measure subjective well-being are not fully applicable to homeless youth. Therefore, as suggested by Diener (2009), it is important to assess the specific components of well-being that are most relevant to the population being studied. Because homeless youth's self-reported subjective well-being may fluctuate widely from day-to-day, and because of the importance of examining psycho-social characteristics of wellness rather than focusing only on happiness and pleasure, the current study will assess well-being using a psychological well-being measure. Psychological well-being has been found to produce more stable scores of well-being than measures of subjective well-being (Burns \& Machin, 2010), while the sub-domains of the psychological well-being measure capture components of social-psychological wellness that can provide a more thorough, stable, and relevant assessment of the well-being of homeless youth.

Unfortunately, very few studies have examined psychological well-being among 
homeless youth. The two known studies to have measured psychological well-being (Taylor et al., 2004; Townley, Pearson, Lehrwyn, Prophet, \& Trauernicht, 2016) have either found significant variability in the well-being scores of their samples, or they did not address important factors that may influence well-being. This study aims to address this gap in the literature, primarily by focusing on intrapersonal and social-contextual factors that may promote the psychological well-being of homeless youth.

\section{Intrapersonal Factors Related to Well-Being}

Well-being research has spread into multiple disciplines, and research has demonstrated associations between well-being and a myriad of outcomes, traits, and experiences, such as personality traits, relationship dynamics, neighborhood resources, and time spent in nature. However, there are specific correlates of well-being that are important to consider within the context of youth homelessness and the specific challenges and circumstances these youth experience. The following section examines intrapersonal factors related to the well-being of homeless youth, including mental health, optimism, and self-esteem.

Mental Health. The World Health Organization (2014) defines mental health as

"a state of well-being in which every individual realizes his or her own potential, can cope with the normal stresses of life, can work productively and fruitfully, and is able to contribute to her or his community" (WHO, 2014). It has also been described as a state in which individuals are both free of psychopathology and flourishing (Keyes, 2002). Although WHO partly defined mental health as a state of well-being, mental illness and well-being have been construed as independent dimensions with their own continua (e.g., 
mental illness to mental health, languishing to flourishing) (Huppert \& Cooper, 2014;

Keyes, 2002; Weich et al., 2011). Indeed, levels of well-being can vary among those with mental illness, with differences in well-being being predicted by both internal and external factors, such as coping style, finances, social relations, and healthcare (Lehman, 1983; Meyer, 2001). Typically, individuals suffering from psychiatric distress have lower levels of well-being than those without mental illness. For example, affective disorders such as depression and anxiety (Diener \& Seligman, 2004), as well as conditions such as schizophrenia (Suslow, Roestela, Ohrmanna, \& Arolta, 2003) are associated with poorer well-being compared to members of the general population.

Thus far, research has been inconclusive as to whether mental illness and wellbeing are mutually exclusive constructs. This is due in part to the fact that many studies aiming to examine well-being do not actually measure well-being or positive outcomes such as positive social functioning or levels of emotional affect - but instead measure a reduction in psychiatric symptomology (Huppert \& Cooper, 2014). The current study considers symptom distress as a component of well-being, but by no means an adequate or exhaustive measure of well-being. This methodological quandary, along with the research cited above proposing that individuals who experience psychiatric distress may have varying levels of well-being, suggests the need to study these associations further. It is particularly important to examine the relationship between mental health distress and psychological well-being among homeless youth given their higher-than-average rates of mental illness.

Optimism. Optimism is defined as a generalized tendency to expect positive 
outcomes even in the face of obstacles (Scheier \& Carver, 1985), and it has been shown to predict numerous components of well-being (Chang \& Sanna, 2001; Diener, Oishi, \& Lucas, 2003; Eid \& Diener, 2004; Makikangas \& Kinnunen, 2003). More specifically, optimism has been associated with greater levels of positive emotional affect, while pessimism has been correlated with more negative emotional affect (Marshall, Wortman, Kusulas, Hervig, \& Vickers, 1992). Further, those who are optimistic tend to utilize problem-focused coping strategies and more effective forms of emotion regulation, both of which can contribute to better overall functioning and well-being, particularly in the face of adversity and intense stressors (Taylor \& Armor, 1996). For example, youth with greater self-regulation tend to have fewer symptoms of anxiety and depression when faced with adverse events (Dishion \& Connell, 2006). Considering that depression and anxiety are associated with lower levels of well-being, this adaptive response to stress may be a key part to explaining optimism's association with well-being.

Research has demonstrated that optimism has a positive impact on the lives of homeless youth (Bender et al., 2007; Usborne et al., 2009), with youth viewing a positive attitude as a key to survival on the streets (Bender et al., 2007). In qualitative interviews, homeless youth have emphasized the importance of seeing adversity as an opportunity for growth, as well as the need to look toward a positive future and remember that their situation is temporary (Kidd, 2003), which is parallel to holding positive expectations in the face of obstacles - i.e., to having an optimistic outlook.

Conversely, studies of adolescents demonstrate that youth who pay little attention to their futures or the long-term consequences of their actions, and who procrastinate 
until consequences determine a course of action tend to have lower levels of optimism and psychological well-being and tend to experience more hopelessness (Phillips \& Pittman, 2007; White, Wampler, \& Winn, 1998). Considering the importance of optimism to well-being (Carver \& Gaines, 1987), it is unsurprising that adolescents with this more negative orientation toward life would have a low level of psychological wellbeing (Adams et al., 2001; Jones, Ross, \& Hartmann, 1992; Nurmi, Berzonsky, Tammi, \& Kinney, 1997; White \& Jones, 1996; White, Wampler, \& Winn, 1998; White, Montgomery, Wampler, \& Fischer, 2003).

Although optimism has been qualitatively reported as intrinsically important to homeless youth (Bender et al., 2007; Kidd, 2003), and has been related to well-being among other populations (e.g., Diener, Oishi, \& Lucas, 2003), no known studies have examined optimism as a direct predictor of psychological well-being among homeless youth.

Self-esteem. Self-esteem is defined as the value one places on the self (Rosenberg, 1965), and high self-esteem has been established as an important correlate and predictor of well-being among a variety of heterogeneous samples and populations (Brown \& Marshall, 2001; Diener \& Diener, 1993; 1995; Diener \& Emmons, 1985; Fordyce, 1988; Kong, Zhao, \& You, 2013; Kreiger, Hermann, Zimmerman, \& Grosse Holtforth, 2015; Lin, 2015a; Lin, 2015b; Rosenberg, Schooler, Schoenbach, \& Rosenberg, 1995). For example, self-esteem has been correlated with general well-being in multiple collectivist and individualistic countries (Diener \& Diener, 1995), as well as with specific components of well-being, such as relationship satisfaction (Andrews \& 
Brown, 1995; Shackelford, 2001). Self-esteem has been related to numerous positive psychological outcomes, such as psychological adjustment, prosocial behavior, and positive affect (Joiner, 1995; Leary \& MacDonald, 2003; Watson, Suls, \& Haig, 2002).

Conversely, adolescents with the above-described negative orientation toward life - which is associated with lower levels of psychological well-being - tend to also have lower levels of self-esteem (Phillips \& Pittman, 2007; White, Wampler, \& Winn, 1998). Homeless youth with low self-esteem are at a greater risk of succumbing to the emotional distress associated with loneliness and feeling trapped, which puts them at a greater risk of negative health outcomes (Kidd \& Shahar, 2008). For example, one study found that self-esteem accounted for $16 \%$ of the variance in suicidal ideation among homeless youth (Cleverley \& Kidd, 2011), while other studies have connected low self-esteem to depression, suicidal ideation, and suicide attempts (Baumeister et al., 2003; Mann, Hosman, Schaalma, \& deVries, 2004).

No known studies have measured self-esteem in direct relation to psychological well-being among homeless youth, nor have optimism and mental health been directly examined in association with measures of well-being within this population. However, based upon research that cites optimism, mental health, and self-esteem as important predictors of well-being among other populations - as well as studies demonstrating the importance of these variables in the lives of homeless youth - a closer examination of these factors in relation to psychological well-being is an important next step in this area of research. 


\section{Social-Contextual Factors Related to Well-being}

Although intrapersonal factors likely play an important role in determining an individual's overall level of well-being, it is equally important to consider socialcontextual factors that may positively impact psychological well-being among youth experiencing homelessness. The community experiences of homeless youth are varied and context-dependent: some youth participate very little with street culture, while others spend the majority of their time immersed in street life and engage very little with mainstream culture (Kidd \& Davidson, 2007). While studies have only recently begun to pay close attention to the social-contextual experiences of homeless youth, some preliminary research suggests the positive role of sense of community, social support, and empowerment as they relate to the well-being of homeless youth.

Sense of community. Sense of community (SOC) includes both the group-level experience of community, as well as the individual experience of sense of community, which is sometimes termed the psychological sense of community (PSOC; Townley, Kloos, Green, \& Franco, 2011). Sense of community has a well-established role in influencing well-being across the lifespan (e.g., Chipuer \& Pretty 1999; Chipuer, Bramston, \& Pretty, 2003; Davidson \& Cotter 1991; Pretty et al. 1996; Royal \& Rossi, 1996; Prezza \& Costantini, 1998; Wilkinson, 1979).

Sarason (1974) described a sense of community as "the sense that one was part of a readily available, mutually supportive network of relationships" (Sarason, 1974, p. 1). Sense of Community (SOC) involves the feeling that members have of belonging; the feeling that members matter to one another and to the group; and the shared belief that 
members' needs will be met through their commitment to being together (McMillan, 1976).

McMillan and Chavis (1986) further delineated four key elements to SOC. First, membership is a feeling of belonging or a shared sense of personal relatedness.

Membership includes boundaries, emotional safety, sense of belonging and identification, personal investment, and a common symbol system. Second, influence includes a sense of mattering, of making a difference to the group, and of the group mattering to its members. Influence includes elements of both conformity and influence, each of which contribute to community cohesiveness. Third, integration and fulfillment of needs includes a feeling that members' needs will be met by the resources they receive as a function of group membership. Needs are often based upon shared values among community members. Finally, shared emotional connection relates to a commitment to and belief that members have shared (and will share) history, common places, time together, and similar experiences. The quality of interactions between group members is particularly important, as the more positive the experience and the relationships developed as a result of contact, the greater the bond (Cook, 1970). Shared emotional connection also requires personal investment in the group, as well as a spiritual bond (McMillan \& Chavis, 1986).

Sense of community (SOC) has been associated with increased psychological well-being (Pretty et al., 1996; Prezza et al., 2001) and perceptions of belonging and community connectedness (Sonn \& Fisher, 1996). Numerous studies have also demonstrated the link between community participation and SOC (Chavis \& 
Wandersman, 1990; Florin \& Wandersman, 1984; Wandersman \& Giamartino, 1980;

Talo, Mannarini, \& Rochira, 2014). Community participation has been shown to strengthen social bonds and sense of belonging in the community, while also enhancing individual and collective well-being (Wandersman \& Florin, 2000). In one of the few studies to directly measure sense of community among homeless youth, Townley and colleagues (2016) found that youth's participation in social, recreational, and vocational activities was significantly related to both their SOC and their psychological well-being.

Conversely, a lower sense of belonging in one's community has been related to higher levels of personal distress and having experienced a greater number of negative life events (Gracia \& Herrero, 2004). While the direction of this relationship is not fully understood, it is likely a bidirectional relationship in the case of youth homelessness. Homelessness typically entails a loss of housing and a disaffiliation from mainstream society and conventional social structures (Zlotnick, Robertson, \& Lahiff, 1999). The longer an individual spends homeless, the greater the chance that they will identify with the culture of street life and the negative social roles ascribed to them by society (Farrington \& Robinson, 1999; Grigsby et al., 1990; Snow \& Anderson, 1987). This disaffiliation may contribute to a lower sense of belonging and identification with housed society, which has the potential to negatively impact youth's well-being and complicate their efforts to transition out of homelessness.

Social support. Social support can include both formal and informal supports and is sometimes defined as an exchange between providers and recipients (Antonucci, 1985; House \& Kahn, 1985; Kahn \& Antonucci, 1980). It can include functional components 
(e.g., emotional support) and structural components (e.g., the size of an individual's social circle), as well as enacted support (e.g., receipt of supportive behaviors) and an individual's subjective perception of support from others (Cohen, 1988; House, Landis, \& Umberson, 1988; Lakey \& Lutz, 1996).

The number and strength of an individual's social connections are two of the strongest predictors of well-being among various populations (Cohen \& Wills, 1985; Dolan et al., 2008; Helliwell \& Putnam, 2004; Pichler, 2006). Further, a growing body of research suggests that effective social support through social connectedness may enhance health and well-being (Cohen \& Wills, 1985; Jetten, Haslam, Haslam, Dingle, \& Jones, 2014). More specifically among homeless individuals, positive social relationships have been found to contribute to well-being (Biswas-Diener \& Diener, 2006), with more recent research suggesting that gains in social support can benefit well-being among individuals utilizing homeless services and housing programs (Johnstone et al., 2016).

Although homeless youth experience persistent challenges related to social exclusion and disaffiliation from conventional social structures, they often develop peer social networks that contribute to a sense of companionship and help them adapt to the complexities of street life (Bender et al., 2007). Social support has been found to be related to well-being in housed adolescents, but this social support is primarily received from family members or other supportive adults (Morgan et al., 2011). Considering that homeless youth typically do not have these types of relationships with their families, they depend on one another rather than on family members, service providers, or authority figures (Karabanow, 2006; Taylor et al., 2004). These networks of "street friends" are 
similar to the nuclear family and fill those missing roles, helping youth to combat feelings of loneliness and alienation while also providing emotional support and assistance (Bender et al., 2007).

Considering that placing trust in close friendships is a buffer against feelings of insecurity and vulnerability (Taylor et al., 2004), peer support networks have the potential to aid the mental-emotional well-being and resilience of homeless youth. Some research suggests that an unexpectedly high level of well-being reported among homeless young adults is due to the size and makeup of their social networks (Taylor et al., 2004; Usborne, Lydon, \& Taylor, 2009).

Empowerment. Finally, empowerment pertains to the ability of individuals and communities that have been marginalized by society to regain control over their own lives (Rappaport, 1987). Empowerment has been found to be related to both sense of community and well-being among youth and vulnerable populations (Friis-Hansen \& Duveskog, 2012). More specifically, active participation in community organizations has been associated with psychological empowerment among youth (Flanagan, 2004; Mazzoni et al., 2014; Youniss \& Yates, 1999; Zimmerman \& Rappaport, 1988). For example, in a study examining sense of community among youth, Evans (2007) found that young people feel a stronger self-described sense of community in contexts where they experience voice and resonance, some power and influence, and adequate support and challenge from adults - all of which are social processes related to empowerment. Youth who are supported by adults in community decision making are more likely to demonstrate greater confidence and agency, increased community connections, and a 
greater sense of empowerment (Krauss et al., 2014).

Although empowerment has not been studied extensively among youth experiencing homelessness, empowerment theories have been used to guide studies and interventions with both youth and adults in a variety of domains, including community organizing, disease prevention, and creating coalitions to enact policy change (Peterson, Peterson, Agre, Christens, \& Morton, 2011). In one of the few published studies to examine empowerment of homeless youth, Ferguson, Kim, and McCoy (2011) suggested that greater ownership of service programs among youth and involvement in agency decision making may increase their sense of community, enhance their motivation to participate actively in agency programming, and encourage them to improve their lives.

Given the positive associations between empowerment and well-being reported in studies of other vulnerable populations (e.g., Friss-Hansen \& Duveskog, 2012), it is likely that empowerment can also positively impact well-being for homeless youth, helping them influence the services and settings in which they participate and eventually transition out of homelessness. Unfortunately, young people are often excluded from having a voice in their communities, while those who do have opportunities for involvement tend to come from more privileged backgrounds. This often excludes those who could potentially benefit most from developing a sense of belonging and purpose (Evans, 2007), including homeless youth. 


\section{Problem Statement}

The experience of well-being is varied both among homeless youth as a group and for homeless youth in relation to housed youth. Among youth experiencing homelessness, the bidirectional relationships between familial breakdown, reduced academic achievement, mental illness, and homelessness itself all contribute to the unfortunately poorer physical, mental, and emotional health prognoses for members of this population. Although there are both intrapersonal and contextual factors associated with well-being that many homeless youth report as being important to them, scores on standardized measures of well-being among this population are inconsistent.

Furthermore, though homeless youth may cite certain characteristics associated with well-being as being important to their survival on the streets, few studies have empirically examined these factors as they relate to their psychological well-being. Moreover, few studies have asked homeless youth directly about which factors they believe to be most important to influencing their well-being. This study aims to address these gaps in the literature by examining associations of both intrapersonal and socialcontextual factors with psychological well-being, as well as by asking youth to describe additional factors that impact their well-being.

It is important to examine well-being among homeless youth because a more accurate understanding of their well-being can inform the services offered to them as they work toward transitioning out of homelessness. Information about factors related to wellbeing can also inform the development of interventions aimed at enhancing well-being among homeless youth, which may aid in their ability to effectively cope with the 
numerous stressors they face. Furthermore, information gained from asking youth about their own well-being can inform the development of more specific and relevant measures to be used among this population, which has the potential to extend to other youth who also fall within marginalized or disadvantaged groups.

\section{Study Purpose, Research Questions, and Hypotheses}

Given the myriad of stressors faced by homeless youth as they navigate life on the streets, it is important to enhance our understanding of psychological well-being among members of this population. The current study examines relationships between homeless youth demographics and well-being, as well as intrapersonal and social-contextual correlates of well-being. The study also collects data from youth about the factors they believe to be most influential to their sense of well-being. More specifically, this study aims to address the following questions:

\section{Research Questions}

Research Question 1: What is the relationship between psychological wellbeing and demographic characteristics of homeless youth, including race, gender, and sexual orientation? Few studies have examined the relationship between demographic characteristics and psychological well-being among homeless youth. Therefore, rather than testing specific a priori hypotheses, the demographic analyses will be exploratory and serve the dual purpose of 1) Contributing to the limited research literature, and 2) Determining whether any demographic variables should be controlled for in the subsequent regression analyses.

Research Question 2: What is the relationship between psychological well-being 
and the following hypothesized intrapersonal correlates of well-being: mental health, optimism, and self-esteem? The following hypotheses are based on previous research among homeless youth and other populations, as reviewed above:

RQ2 Hypothesis 1: Self-esteem will be significantly positively related to psychological well-being, such that higher reported self-esteem will be associated with greater well-being.

RQ2 Hypothesis 2: Mental health will be significantly positively related to psychological well-being, such that better mental health will be associated with greater well-being.

RQ2 Hypothesis 3: Optimism will be significantly positively related to psychological well-being, such that higher levels of optimism will be associated with greater well-being.

Research Question 3: What is the relationship between psychological well-being and social-contextual correlates of well-being: sense of community, social support, and empowerment? The following hypotheses are based on previous research among homeless youth and other populations, as reviewed above:

RQ3 Hypothesis 1: Empowerment will be significantly positively relatively to psychological well-being, such that higher levels of empowerment will be associated with greater well-being.

RQ3 Hypothesis 2: Sense of community will be significantly positively relatively to psychological well-being, such that higher levels of sense of community will be associated with greater well-being. 
RQ3 Hypothesis 3: Social support will be significantly positively relatively to psychological well-being, such that a greater number of reported social contacts and greater satisfaction with these contacts will be associated with greater well-being.

Research Question 4: What is the relative influence of intrapersonal and socialcontextual factors in predicting psychological well-being of homeless youth (Figure 1)?

RQ4 Hypothesis: When examined collectively, intrapersonal factors will account for more of the variance in psychological well-being than contextual factors.

This is the first known study to empirically examine the relative importance of intrapersonal and social-contextual factors in predicting psychological well-being among homeless youth. Although psychological well-being includes components that are related to both internal and social components of healthy psychological functioning, it is still a subjective measure of an individual's internal perception of their own functioning (Ryff \& Keyes, 1995), and therefore will likely be more closely related to internal constructs, such as mental health, optimism, and self-esteem. Moreover, in line with ecological systems theory (Bronfenbrenner, 1979), it is likely that the intrapersonal factors will account for additional variance in well-being above and beyond the influence of more distal factors such as sense of community and social support because they are more proximal to an individual's overall level of psychological functioning and wellness.

Research Question 5: What factors do homeless youth identify as influencing their sense of well-being? 
Finally, qualitative data from youth regarding factors that influence their wellbeing may be important in identifying additional aspects of their lives that help them remain well despite the many stressors they experience. It is expected that youth will identify a variety of both intrapersonal and social-contextual factors that impact their well-being.

Information gained from these five questions can guide multiple efforts to better serve youth experiencing homelessness. Quantitative analyses will help to determine which factors are most closely related to well-being among homeless youth, as well as the relative importance of each type of factor to the psychological well-being of this population. Qualitative data analysis has the potential to contextualize quantitative findings while also informing other potential predictors of well-being that should be included in future research. In line with Morgan's (1998) recommendations regarding being explicit about priority and sequencing decisions when combining quantitative and qualitative methodologies, this study prioritizes quantitative data and uses qualitative data as a complimentary source of information to contextualize and expand upon what is learned from the primary quantitative component of the study. Moreover, results will provide information about ways that service centers can make improvements in their efforts to enhance well-being and associated factors, including self-esteem, sense of community, and empowerment. Helping service centers better understand the well-being of homeless youth can promote services that both emphasize the components of wellbeing that youth value and deem pertinent to their current circumstances, while also aiding in the development of programs aimed at enhancing the overall well-being of 
homeless youth. Finally, study findings can inform prevention and health-promotion interventions and programs directed toward assisting homeless youth, which have the ultimate goal of helping youth transition to a more stable and secure life, as well as preventing them from experiencing homelessness as adults. 


\section{Methods}

\section{Participants}

Participants in this study were 100 homeless youth who utilize services in Portland, Oregon. National surveys estimate that $87.4 \%$ of unaccompanied homeless youth are ages $18-24$, and the other $12.6 \%$ are under the age of 18 (Annual Homeless Assessment Report to Congress, 2015). The majority of homeless youth who utilize services in Portland are ages 18 to 24, with recent studies in the region finding the average age to be 21 (e.g., Townley et al., 2016). Further, the survey questions required a level of self-reflection, maturity, and deliberate engagement that is more likely to occur among youth in this age range as opposed to youth who are 12 to 17 . Therefore, only youth over the age of 18 were recruited for participation in this study.

Participants were recruited via in-person invitation and informational flyers at p:ear (project: education, art, and recreation), a nonprofit community center that provides mentoring services to homeless youth in Portland. Convenience sampling was necessary in order to reach the desired number of participants. The PI worked with staff at p:ear to recruit potential participants (e.g., checked with staff to ensure youth were within the required age range). Staff were fully briefed on the study prior to dissemination of flyers so that they were equipped to answer questions from potential participants. If they were unable to answer questions, they referred interested participants to the research team.

Demographics and participant characteristics. In this sample $(N=100), 68 \%$ of participants identified as male; $67 \%$ as heterosexual; and $52 \%$ as white (see Table 1). Age ranged from 17 to 25 , with the mean age being $21.42(S D=2.09)$. The age at which 
youth became homeless ranged from one to 23 , with a mean of $16.53(S D=2.09)$.

Participants reported an average of $4.63(S D=11.27)$ lifetime episodes of homelessness; and the current length of homelessness ranged from one week to 12 years $(M=20.63$ months, $S D=27.93)$. Participants were asked how they became homeless this most recent time, and the most common reason was being "kicked out" of their previous homes $(n=36)$. The second most common reason was choosing to leave $(n=29)$. Youth also cited personal problems ( $n=14)$ (e.g., "drug relapse, lost everything" "got pregnant and was dropped off in the city"), financial difficulties $(n=11)$, choosing to travel ( $n=$ $6)$, and difficulty finding housing $(n=4)$. Numerous participants $(n=39)$ mentioned familial factors as part of the reason they became homeless. For example, youth cited abuse from family members, an unhealthy living environment, and differences in beliefs or morals as their reasons for either being kicked out or choosing to leave their homes.

\section{Measures}

Psychological well-being. Psychological well-being was measured using the Psychological Well-Being Scale (Ryff \& Keyes, 1995), an 18-item measure assessing autonomy, environmental mastery, personal growth, positive relations with others, purpose in life, and self-acceptance (e.g., "I gave up trying to make big improvements or changes in my life a long time ago," "I have confidence in my opinions, even if they are contrary to the general consensus"). Participants responded using a six-point Likert scale ranging from strongly disagree to strongly agree. This measure demonstrated sufficient internal consistency (0.82) in a previous study of homeless youth (Townley et al., 2016) as well as in the current study $(\alpha=0.76)$. 
Mental health. Mental health was measured using the Kessler-6 scale, which assesses severity of psychological distress and was designed to estimate the proportion of serious mental illness within the general population (Kessler et al., 2002). The six items ask participants how often they felt nervous, hopeless, restless, depressed, worthless, or that everything was an effort over the past 30 days. Items are rated on a 1 to 5 Likert scale $(1=$ all of the time, $5=$ none of the time $)$. The Kessler- 6 has established reliability and validity and has been used within a variety of populations both in the United States and internationally (Kessler et al., 2002). The internal consistency for this scale in the current study was adequate $(\alpha=0.78)$.

Optimism. Optimism was measured with the Life Orientation Test Revised (Scheier, Carver, \& Bridges, 1994), a scale originally developed to assess individual differences in generalized optimism versus pessimism ("In uncertain times, I usually expect the best"). It is a six-item measure with each item rated on a 5-point Likert scale from $1=$ strongly agree, to $5=$ strongly disagree. The LOTR has been used in a variety of research with multiple populations demonstrating good reliability and validity (see Carver, Scheier, \& Segerstrom, 2010 for a review), and had adequate internal consistency in this sample $(\alpha=0.76)$.

Self-esteem. Self-esteem was assessed with the Rosenberg Self-Esteem Scale (Rosenberg, 1965), a 10-item scale that measures global self-worth by assessing both positive and negative feelings about the self ("I feel that I am a person of worth, at least on an equal plane with others"). Items are answered on a 4-point Likert scale from strongly agree to strongly disagree. More recent studies have confirmed the reliability 
and validity of this scale (e.g., Gray-Little, Williams, \& Hancock, 1997), and the scale demonstrated good internal consistency in the current study $(\alpha=0.85)$.

Sense of community. Perceptions of sense of community were assessed using the Sense of Community Index-2 (SCI-2; Chavis, Lee, \& Acosta, 2008). Participants respond to 24 items assessing perceptions of community membership, influence, fulfillment of needs, and shared emotional connection (e.g., "I get important needs of mine met because I am part of this community," "being a member of this community is part of my identity"). Responses are indicated using a four-point Likert scale ranging from "not at all" to “completely." Multiple studies across different cultures and types of communities have utilized this measure and demonstrated its validity and reliability (Chavis, Lee, \& Acosta, 2008). For this study, participants were given a general instruction to answer questions in relation to the areas of Portland in which they spend the most time. The scale demonstrated a high level of internal consistency in the current study ( $\alpha=0.91)$.

Social support. While social support has been measured in a variety of ways in the literature, this study measured youth's social support networks using the following three indicators: 1) how many family members the participant can turn to for support; 2) how many friends the participant can turn to for support; and 3) how many other adults the participant can turn to for support. In addition to reporting the total number of supports in each category, participants were also asked to rate their satisfaction with the relationship on a 5-point Likert scale ranging from "very dissatisfied" to "very satisfied." The measure is similar to the commonly used Social Support Questionnaire (SSQ) developed by Sarason and colleagues (1983). However, while the SSQ asks participants 
to list up to nine individuals who provide support for specific circumstances or purposes, we were more interested in more general provision of support. Further, the SSQ limits the participant to naming 9 supports for a given domain, while we were interested in allowing participants to name as many supports as possible in the given categories.

Total Social Support scores for each participant were obtained by the following process: first a product was obtained between network size and satisfaction for each category (i.e., family members, friends, and other adults); second, the product scores across the three support categories were summed to yield a weighted social support score (i.e., a measure of the total number of supports weighted by the satisfaction the participant has with each type of support). This scaling was employed to capture the importance of both the quantity and the quality of support networks.

Empowerment. Empowerment was measured using the 17-item Sociopolitical Control Scale for Youth (Peterson et al., 2011). Items assess leadership competence (e.g., "I can usually organize people to get things done") and policy control (e.g., "youth like me have the ability to participate effectively in community activities and decision making") and are answered on a 5-point Likert scale from strongly agree to strongly disagree. This scale has been used with multiple youth populations internationally (Peterson et al., 2011). While previous studies have often used this scale as an intrapersonal measure, it was conceptualized in this study as a social-contextual variable given the fact that questions ask youth about their ability to influence other people and places. The scale demonstrated good internal consistency in the current study ( $\alpha=0.83)$. 
included to provide additional context for the quantitative findings. Participants were asked to describe factors that are most influential to their well-being. All participants were asked to name at least one factor, but some youth reported up to five factors.

\section{Design and Procedures}

This study utilized a cross-sectional design and survey methodology. Approval for the study was granted by the Portland State Internal Review Board in April 2017. Data were collected in a one-on-one interview format. Participants responded verbally to survey measures administered by a researcher, who then recorded their responses electronically using iPads. Considering the mobility of this population, the researchers anticipated that most youth would wish to complete the interview immediately, as opposed to scheduling it for a later time. The PI worked with a team of two research assistants to help conduct as many interviews at the time youth were recruited as possible. If interviews could not be conducted at the time of recruitment (typically due to the researchers conducting other interviews or because the service center was closing), they were scheduled for a later time or date. Interviews took an average of thirty minutes to complete, and they were conducted in a semi-private common area. This ensured that the participants were not distracted by activities or noise in the main room of the service center, and also allowed for as much privacy as possible when responding to questions.

Before beginning the interview, youth were asked to read and sign an informed consent document specifying that participation was entirely voluntary and would not impact any services they may be receiving. All survey item responses were kept entirely confidential. Given that no deceptive or invasive procedures were employed, a formal 
debriefing process was not determined to be necessary. However, all youth received a copy of the informed consent, and the PI and/or research assistants answered any questions that they had before, during, and following their involvement. Youth received $\$ 10$ cash for completing the survey, as cash incentives provide more flexibility and autonomy than gift cards. 


\section{Results}

\section{Data Preparation, Screening, and Preliminary Analyses}

Research questions and hypotheses were analyzed using SPSS Version 24 (IBM Corporation, 2016). Continuous composite scores of individual variables were computed for all scales, and demographic variables were categorized into binary variables (e.g., male/ non-male $\left.{ }^{1}\right)$. Listwise deletion was planned for cases in which participants were missing more than $25 \%$ of the data on any single measure included in the analyses. However, issues concerning missing data were minimal, and no participants were missing more than $25 \%$ of the items in any given scale (and the vast majority of participants were missing no data at all). Thus, no participants were removed from the dataset due to missing data. Initial descriptive statistics were conducted to identify outliers in the primary study variables as well as potential errors in data collection or entry. Two participants were subsequently removed from the dataset because their ages were above the limit for the study.

Descriptive statistics and frequency distributions were then examined to confirm that variables were normally distributed and fell within a plausible range of values (see Table 2). Distribution analyses revealed that most variables were normally distributed and within a conservative range for skewness and kurtosis $(|s|<1,|k|<3)$ (George \& Mallery, 2010). Tests of skewness and kurtosis revealed that the social support variable was positively skewed and peaked (see Table 2). A separate analysis using a logarithmic

\footnotetext{
${ }^{1}$ Given the small percentage of those who identified as female, transgender, non-binary, and gender fluid. gender was coded as a dichotomized variable instead of retaining separate groups in order to protect the identities of all participants.
} 
transformation of this variable did not substantively alter the results, and the skewness and kurtosis values were within an acceptable range according to less stringent guidelines $(|s|<3,|k|<10)($ Kline, 2011). Thus, a decision was made to leave this variable untransformed in order to maintain the interpretability of the results.

Table 3 presents a correlation matrix of all study variables. All independent variables had moderate (i.e., $0.3 \leq|\mathrm{r}|<0.7$ ) to strong (i.e., $|\mathrm{r}|>=0.7$ ) significant correlations with the outcome variable (psychological well-being). None of the correlations between independent variables exceeded $|\mathrm{r}| \geq 0.8$, which would be means for investigating multicollinearity (Berry \& Feldman, 1985). Although not part of the formal research questions, preliminary analyses were also conducted to assess potential associations between youth's reported experiences with homelessness and psychological well-being. Neither age of first episode of homelessness nor total number of times homeless were significantly correlated with well-being $(r=-.04, p=.68$ and $r=-.06, p$ $=.56)$. Similarly, length of time currently homeless was not significantly related with participants' well-being $(r=-.16, p=.12)$.

\section{Quantitative Data Analyses and Results}

Research Question 1: What is the relationship between psychological well-being and demographic characteristics of homeless youth, including race, gender, and sexual orientation?

Pearson correlation and independent samples $t$-tests were conducted to examine associations between participant demographics and psychological well-being. Age was not significantly associated with psychological well-being $(r=-.05, p=.65)$. There were 
no significant differences in psychological well-being between white participants $(M=$ 4.46, $S D=0.66)$, and non-white participants $(M=4.32, S D=0.63), t(98)=1.08, p=$ .28. Similarly, participants who identified as heterosexual did not have significantly different psychological well-being scores $(M=4.42, S D=0.61)$ than participants who did not identify as heterosexual $(M=4.35, S D=0.72), t(98)=1.08, p=.59$. However, psychological well-being was significantly greater among male participants $(M=4.49$, $S D=0.59)$ than non-male participants $(M=4.20, S D=0.72), t(98)=2.15, p<.05$. Based on these findings, gender was entered as a covariate in the subsequent regression analyses, while the other demographic variables were not included given their lack of association with well-being and based on concerns about having sufficient power to detect effects given the number of variables in the analyses.

Research Question 2: What is the relationship between psychological well-being and the following hypothesized intrapersonal correlates of well-being: mental health, optimism, and self-esteem?

RQ2 Hypothesis 1: Self-esteem will be significantly positively related to psychological well-being, such that higher reported self-esteem will be associated with greater wellbeing.

RQ2 Hypothesis 2: Mental health will be significantly positively related to psychological well-being, such that better mental health will be associated with greater well-being. RQ2 Hypothesis 3: Optimism will be significantly positively related to psychological well-being, such that higher levels of optimism will be associated with greater well-being. 
Research Question 3: What is the relationship between psychological well-being and the following hypothesized social-contextual correlates of well-being: sense of community, social support, and empowerment?

RQ3 Hypothesis 1: Empowerment will be significantly positively relatively to psychological well-being, such that higher levels of empowerment will be associated with greater well-being.

RQ3 Hypothesis 2: Sense of community will be significantly positively relatively to psychological well-being, such that higher levels of sense of community will be associated with greater well-being.

RQ3 Hypothesis 3: Social support will be significantly positively relatively to psychological well-being, such that a greater number of reported social contacts and greater satisfaction with these contacts will be associated with greater well-being.

Research questions two and three were assessed by conducting two linear regressions. In Model 1, psychological well-being was regressed on the intrapersonal variables (psychological distress, self-esteem, and optimism) while controlling for gender. In Model 2, psychological well-being was regressed on the social-contextual factors (sense of community, social support, empowerment) while controlling for gender.

Model 1: $\gamma(\text { psychological well-being })_{i}=\beta_{0}+\beta_{1}(\text { gender })_{i}+\beta_{2}(\text { self-esteem })_{i}+\beta_{3}$ $(\text { psychiatric distress })_{i}+\beta_{4}(\text { optimism })_{i}+$ Error

Model 2: $\gamma(\text { psychological well-being })_{i}=\beta_{0}+\beta_{1}(\text { gender })_{i}+\beta_{2}(\text { empowerment })_{i}$ $+\beta_{3}(\text { sense of community })_{i}+\beta_{4}(\text { social support })_{i}+$ Error 
Results indicate that intrapersonal variables (Model 1) accounted for $56 \%$ of the total variance in psychological well-being, $F(4,95)=30.30, p<.001$. Psychological distress and self-esteem were significant predictors of psychological well-being, while optimism was not (see Table 4).

Similarly, the Model 2 regression with social-contextual variables predicting psychological well-being was significant, $F(4,95)=8.78, p<.001$. The model accounted for $27 \%$ of the total variance in psychological well-being. Empowerment and social support were significant predictors of psychological well-being, while sense of community was not (see Table 5).

Research Question 4: What is the relative influence of intrapersonal and contextual factors in predicting psychological well-being of homeless youth? RQ4 Hypothesis: When examined collectively, intrapersonal factors will account for more of the variance in psychological well-being than contextual factors.

Research question four was assessed by conducting a hierarchical linear regression. Predictors were added in blocks, and the resulting change in R-squared values, as well as the beta-weights for each individual variable, were assessed. The first block contained only gender, as it was the only demographic variable significantly related to the outcome variable in the analyses corresponding with research question 1. Psychological distress, self-esteem, and optimism were entered in the second block of predictors. And, finally, sense of community, social support, and empowerment were entered in the third block of predictors.

Block 1: Gender 
Block 2: Psychological distress, self-esteem, and optimism

Block 3: Sense of community, social support, and empowerment

Model 3: $\gamma(\text { psychological well-being })_{i}=\beta_{0}+\beta_{1}(\text { gender })_{i}+\beta_{2}(\text { self-esteem })_{i}+\beta_{3}$ $(\text { psychiatric distress })_{i}+\beta_{4}(\text { optimism })_{i} \beta_{5}(\text { empowerment })_{i}+\beta_{6}($ sense of community $)_{i}+\beta_{7}(\text { social support })_{i}+$ Error

The full hierarchical model was significant, accounting for $57 \%$ of the variance in psychological well-being, $F(7,92)=17.99, p<.001$ (see Table 6$)$. In block 1 , gender accounted for $4.5 \%$ of the variance in the model and was significantly negatively related to psychological well-being $(\beta=-.21, p<.05)$, indicating that males experienced significantly greater psychological well-being that non-male identified participants. The inclusion of intrapersonal variables in block 2 accounted for an additional 52\% of the variance $(p<.001)$. Of the intrapersonal variables, self-esteem was significantly positively related to well-being $(\beta=.65, p<.001)$, while psychological distress was significantly negatively related to psychological well-being $(\beta=-.27, p<.05)$. Optimism was not a significantly predictor of well-being $(\beta=-.11, p=.31)$. The addition of the social-contextual variables in block 3 did not account for a significant amount of additional variance $\left(\Delta R^{2}=.02, p=.31\right)$. In the final model with all intrapersonal and social-contextual variables included, self-esteem $(\beta=.56, p<.001)$ and psychological distress $(\beta=-.26, p<.05)$ were the only significant predictors of psychological wellbeing.

Collinearity statistics were assessed in each regression model. Most Variance Inflation Factor (VIF) values were below conservative cut-off recommendations (VIF < 
2), while all VIF values were below less conservative, but still acceptable, recommendations (VIF < 5) (Craney \& Surles, 2002).

\section{Qualitative Data Analysis and Results}

Research Question 5: What factors do homeless youth identify as influencing their sense of well-being?

Participants were asked to describe factors that contribute to their overall wellbeing. Responses to this open-ended question were analyzed using a combination of semantic and inductive thematic analysis (Boyatzis, 1998), as the intention was to explore and better understand youth's perspective on what contributes to their well-being. A semantic approach includes identifying which themes are within the explicit or surface meanings of the data (Berg, 2004), while an inductive approach incorporates identification of themes or dimensions that reflect participants' words and experiences rather than coding data according to pre-existing theoretical frameworks (Braun \& Clarke, 2006).

The principal investigator coded responses using a low level of inference; that is, codes were assigned based on the participants' words rather than the PI's preconceptions or assumptions (Huberman \& Miles, 2002). The investigator familiarized herself with the data and engaged in an iterative process to create a list of twenty-one phrases or words that captured participants' responses to the open-ended question. These were then categorized into eleven thematic categories that were used to code the individual responses. If the investigator was unsure of how to code a response, the response was marked, and these cases $(n=25)$ were discussed with a faculty advisor to reach 
consensus about how it should be coded. This discussion also prompted the refinement of a few of the thematic categories in order to more accurately categorize participants' responses. For example, Sense of Purpose was changed to Sense of Purpose and Responsibility to reflect youth's suggestions that their sense of purpose often stemmed from their sense of responsibility to others (e.g., to a child, a pet, or friends).

On average, participants listed 2.66 factors that influence their well-being, with a range of one to five factors. Findings are summarized according to the following thematic categories: 1) Social Support, 2) Self-Care, 3) Personal Outlook, 4) Recreational Activities, 5) Service Centers, 6) Sense of Purpose and Responsibility, 7) Learning or Growth, 8) Self-Expression, 9) Vocational Activities, 10) Having Goals, and 11) Spiritual Beliefs. Information pertaining to both the content of these themes as well as the frequency with which they were reported by youth can be found in Table 7 .

Social Support was the most frequently coded category, with 62 participants providing 88 responses that included both specific types of social support, such as friends and family members, as well as more general reflections on the importance of relationships and community to well-being (e.g., "friends who encourage me," "family support," "community"). Self-Care was the second most frequent response, with 24 participants providing 37 responses related to having basic needs met (e.g., food, water, shelter), having structure or routine, personal health and hygiene, as well as exercise, sleep, and maintaining a sober lifestyle (e.g., "taking care of myself" "improvement in my medical care"). The third most frequently reported category was Personal Outlook, which included participants' reflections about personal perspectives, internal motivations, and 
core values that impact well-being (e.g., "resisting negativity from others" "maintaining my personal values" "hope for the future"). A total of 32 responses from 23 participants were coded in this category.

Recreational Activities (29 responses from 20 participants) and Service Centers (26 responses from 25 participants) were the next two most frequently reported categories. Recreational Activities included outdoor activities, music and art, reading, and other hobbies. Responses that were coded into the Service Center category were based on specific references to local youth service centers that impact youth's well-being, such as the community center from which these data were collected. The remaining categories were coded less frequently (fewer than 15 times) and are summarized in Table 7. 


\section{Discussion}

The results of this study can guide multiple efforts to better serve and support homeless youth. Given the myriad of stressors faced by homeless youth as they navigate life on the streets and work to access housing, education, and employment, it is important to enhance our understanding of psychological well-being among members of this population. Research with youth experiencing homelessness has typically focused on their challenges, setbacks, and negative outcomes (e.g., rates of mental illness, problem behaviors) as opposed to their strengths and positive outcomes - their resilience in the face of adversity. This study's exploration of psychological well-being among homeless youth can add to the emerging research literature aimed at highlighting youth's strengths and resilience, and in particular can help to illuminate some of the intrapersonal and social-contextual factors that impact the mental-emotional health of homeless youth as they navigate life on the streets.

\section{Study Findings and Implications}

Demographics and participant characteristics. Due to the lack of prior research on how demographic characteristics relate to the psychological well-being of homeless youth, this study did not specify a priori hypotheses and instead took an exploratory route. The demographics of participants in this sample were comparable to a previous study of homeless youth in the same city (Townley et al., 2016). In this sample, gender was the only demographic variable that was significantly related to psychological wellbeing, such that male-identified individuals had greater psychological well-being than participants who identified as female, transgender, non-binary, and gender fluid. 
Considering the marginalization often faced by those who step outside of the genderbinary norms (e.g., Cochran, Stewart, Ginzler, \& Cauce, 2002), this could be one of the reasons why the psychological well-being of these individuals was lower. Moreover, females who are homeless may face certain difficulties, stressors, and dangers that those who are male do not face, which can be a detriment to their psychological well-being. For example, sexual minorities face a greater risk for developing emotional disorders and psychological distress (Hatzenbuehler, McLaughlin, \& Nolen-Hoeksema, 2008; Makadon, 2011), are more likely to engage in substance abuse (Ramirez-Valles, Garcia, Campbell, Diaz, \& Heckathorn, 2008), and are more likely to be physically, verbally, and sexually abused by others who are intolerant of their identities (Khan et al., 2009). These results suggest the importance of services that are focused on supporting individuals with gender-related needs, with a specific emphasis on the needs of female, transgender, and non-gender-binary youth.

This study did not find psychological well-being to be related to age, sexual orientation, or racial background among homeless youth. This latter finding is contradictory to a previous study in the same city (Townley et al., 2016), which found significant differences in psychological well-being between white and non-white youth. Potential reasons for this discrepancy, as well as future directions for understanding how race may relate to psychological well-being among youth experiencing homelessness, are discussed in the limitations section.

Finally, although not a primary focus of this study, preliminary analyses suggested no associations between psychological well-being and participants' reported 
length of time homeless, age of first homelessness, or number of times spent homeless.

While previous studies have reported significant associations between psychiatric distress and amount of time spent homeless (e.g., Castellow et al., 2015), the null findings in the current study may reflect the more stable nature of psychological well-being in comparison to psychiatric distress (Massé et al., 1998), as well as the likelihood that wellbeing is more strongly associated with intrapersonal phenomena than with situational or environmental factors, as will be discussed in more detail below.

Intrapersonal predictors of psychological well-being. While optimism, psychological distress, and self-esteem were significantly associated with psychological well-being at the bivariate level, optimism was not a significant predictor when examined alongside other intrapersonal factors in a regression model. Optimism has the potential to help youth maintain hope and positive affect during times of adversity, both of which can contribute to subjective well-being (e.g., Carver \& Gaines, 1987). A few studies have also linked greater optimism and lower pessimism to better psychological well-being outcomes after facing adversity (e.g., Cohen, 1990). Future studies should examine whether and how optimism might benefit psychological well-being of youth experiencing homelessness, as well as how this might impact their long-term resilience. While optimism was not a significant predictor of psychological well-being, it was still significantly associated in bivariate analyses, which points to the need for further research that examines these constructs more closely in youth populations facing adversity. 
On the other hand, psychological distress was a significant predictor of psychological well-being, such that lower psychological distress predicted greater psychological well-being. Considering that psychological well-being is a measure of positive psychological functioning, while psychological distress would indicate low psychological functioning, this result is unsurprising while also supporting the notion that psychological health is a distinct construct from psychological well-being (Provencher \& Keyes, 2011). More specifically, the association between psychological distress and psychological well-being was moderate in size, and thus it is possible that youth may experience minor to moderate levels of psychological distress while still having aboveaverage levels of psychological well-being. However, further research is needed to understand the nuances of this relationship and how to promote the long-term resilience and well-being of youth experiencing homelessness. For example, future research could examine variations in levels and types of psychiatric distress among homeless youth with higher and lower psychological well-being, or could utilize qualitative methods to examine how youth do or do not maintain their well-being despite experiencing psychiatric distress. Findings also suggest a more general need for continued research and service program development to address the higher-than-average rates of mental health distress among youth experiencing homelessness (Kamieniecki, 2001; Moore, 2005; Slesnick \& Prestopnik, 2005).

Self-esteem was the strongest intrapersonal predictor of psychological well-being. Considering that homeless youth are typically in the developmental stage of late adolescence and emerging adulthood (e.g., Arnett, 2006), self-esteem may be one of the 
driving factors behind the development of the specific components of psychological wellbeing (i.e., self-acceptance, autonomy, mastery of the environment, positive relationships, purpose in life, and continued growth). Emerging adulthood is a crucial period for identity development, as well as a time when young people develop a sense of autonomy and competence and cultivate close friendships outside of the family (Arnett, 2006; Erikson, 1950; Erwin, 2014). Low self-esteem could create identity confusion among youth and contribute to a lack of confidence in their own worth or abilities, as well as decreased levels of self-acceptance. With this in mind, lower self-esteem could also inhibit youth from trying to cultivate positive relations with others, as they may feel unworthy of, or unable to develop, close relationships. Alternatively, low self-esteem may also make youth more vulnerable to negative social influences, such as engaging in violent activities or abusing drugs and alcohol (Maccio \& Schuler, 2011).

Moreover, previous research has cited self-esteem as an important correlate of resilience across the lifespan (e.g., Prince-Embury \& Saklofske, 2013), and the crucial protective role that self-esteem may have for the resilience of homeless youth in particular (Kidd \& Shahar, 2008). Previous research has found homeless youth to emphasize a reliance on the self in order to remain resilient. Youth's ability to depend on their own self-resources may be directly related to their self-esteem, such that those who have lower self-esteem may experience a heightened vulnerability to negative psychological health outcomes, such as depression and suicide (Kidd \& Shahar, 2008). Thus, self-esteem may be a factor that promotes self-reliance and autonomy among homeless youth, which in turn could protect their psychological well-being. The findings 
of this study highlight the need for interventions and services that help youth work through past and present threats to self-esteem, while also building capacities for valuing and relying on the self.

Social-contextual predictors of psychological well-being. Results indicated that empowerment and social support were significant predictors of psychological well-being, while sense of community was not. Empowerment may be an important predictor of psychological well-being among homeless youth because it could encourage youth to take initiative in developing autonomy and gaining mastery over their environments. This is especially important to consider for youth who display a sense of agency in leaving abusive homes or dangerous circumstances for the sake of their own health and safety. These youth may view homelessness as a situation that they are in control of and that supports their autonomy, and thus feel empowered in their experiences of homelessness. Furthermore, a sense of empowerment could also contribute to a sense of purpose and meaning in the lives of homeless youth if they see themselves as being able to make positive changes in their communities, and if service centers and outreach programs support youth in taking control of their lives, setting goals, and working toward these positive changes.

Social support was also a significant predictor in the regression analysis examining social-contextual factors related to psychological well-being. Social support provided by service center programs may aid youth in their development of autonomy and mastery, while also fostering their personal growth. Further, these supports may provide youth with opportunities to develop positive social relationships, whether with 
the service center staff or with other youth who visit the service centers. Developing peer friendships is acutely important to adolescents and emerging adults as they begin to break away from their families and establish autonomy (e.g., Arnett, 2006). These social relationships may be particularly important to the well-being of youth experiencing homelessness, as these friendships may be their primary sources of support, particularly if they are disconnected from their families. While youth who are not homeless may be able to gradually transition to a greater dependence on the self and to relationships outside of the family system, homeless youth often have to make this adjustment more quickly and may have to rely more heavily on social supports developed within service centers and peer groups.

Another important consideration is that social support in the form of close peer friendships may provide youth with a sense of motivation, responsibility, emotional validation, and peer-to-peer understanding, all of which may contribute to the psychological well-being of homeless youth. It is likely that social support has both direct and indirect effects on psychological well-being, though more research is needed to discern the mechanisms through which social support influences well-being among homeless youth.

Contrary to the hypothesis that higher levels of sense of community would be associated with greater psychological well-being, sense of community was not found to be a significant predictor of well-being when examined alongside the other socialcontextual factors. This could be due in part to the manner in which this measure was introduced to youth. Specifically, participants were asked to answer the sense of 
community questions thinking about the communities where they spend the most time. Thus, while some youth likely thought about the broader Portland community when responding, many youth answered the questions in relation to the homeless youth community, or to areas where they spend time with other homeless youth (e.g., homeless youth service centers). Mallet and colleagues (2005) suggested that engagement with street-based and/or homelessness service cultures can pressure youth to engage in problematic behaviors such as substance abuse. Moreover, disaffiliation from conventional social structures and identification with street life culture can make transitioning out of homelessness more difficult, as research has demonstrated positive associations between the comfort and familiarity of street life and the length of time spent homeless (Piliavin, Sosin, Westerfield, \& Matsueda, 1993).

With these research findings in mind, a lower sense of community may actually be adaptive if over-identification with other homeless youth puts individuals in danger or exposes them to influences that may interfere with their efforts to transition out of homelessness. Further, considering that a shorter history of homelessness is predictive of a greater chance of exiting homelessness and retaining stable housing (Piliavin et al., 1996; Zlotnick et al., 1999), a stronger sense of community with other homeless youth, as well as increased engagement and comfort with street life, may increase the length of time youth spend homeless. In this case, a negative sense of community may be more beneficial to the well-being of some homeless youth. Specifically, Brodsky's (1996) suggestion that a negative sense of community (i.e., distancing oneself from a community) can be an intentionally adaptive behavior may explain why some homeless 
youth choose not to engage with the homeless youth community and, instead, cite the crucial importance of autonomy to their survival (Bender et al., 2007; Kidd, 2003; Kidd \& Shahar, 2008; Rew \& Horner, 2003). What is seen as maladaptive from the typical sense of community standpoint may actually be quite adaptive given the context of street culture.

However, it could also be that sense of community is important to varying degrees at different points during youth's experiences of homelessness, or that the particular communities that youth identify as important to them could differentially impact their well-being at different stages of homelessness. Furthermore, whether a strong sense of community is mutually exclusive with a strong sense of autonomy among homeless youth should be considered for future research, keeping in mind that enhancing autonomy is a crucial developmental task for adolescents and emerging adults. If this is the case, it could be that youth who feel a stronger sense of community with the homeless youth community have a lower sense of autonomy, which may contribute to an overall lower level of psychological well-being. More research is needed to understand the nuances of how autonomy and sense of community may relate to the psychological well-being of homeless youth.

Hierarchical regression predicting psychological well-being. When examined collectively in a hierarchical regression model, the block of intrapersonal variables remained significantly associated with psychological well-being, while the socialcontextual variables were no longer significant. This could be due to the fact that psychological well-being is itself an inherently intrapersonal variable, and thus would 
theoretically be expected to be more strongly related to the other intrapersonal constructs than the social-contextual variables. From a measurement perspective, it is also likely that there are more similarities in the content of items between the intrapersonal predictor variables and the psychological well-being outcome, which may have inflated the size of their associations. Future studies should consider including, or creating, measures of well-being and its hypothesized correlates that are more conceptually distinct. Including multiple respondents (e.g., service staff, peers) and types of measurement (e.g., observational data, service use data) may also help address this issue of common methods variance.

Although self-esteem and psychological distress were the primary significant predictors in the hierarchical regression, it is important to be cautious when interpreting this finding. These results should not place the full responsibility for psychological wellbeing on the individual youth, nor should they be used to conclude that a lack of psychological well-being is the "fault" of the individual. Various experiences in early life can help to shape the self-esteem and mental health of an individual, and environmental factors that interact with the person over time can also contribute to these intrapersonal variables and outcomes of well-being. These results suggest the importance of providing homeless youth with the opportunities to develop a stronger self-esteem and with resources that can support their mental-emotional health. For example, as discussed above, services centers can provide youth with opportunities to develop skills and support them in achieving their goals. This, in turn, may help youth develop greater levels of selfesteem, which could further enhance their psychological well-being. 
Open-ended well-being responses. The open-ended question asking youth to list factors that contribute to their overall well-being suggested that social support was a prominent contributor to youth's well-being, which corresponds with results from the regression analyses. Youth specifically mentioned the importance of friends, "street family," and romantic partners as contributing to their overall well-being. This supports previous research suggesting the importance of social support to well-being more generally (e.g., Cohen \& Wills, 1985; Jetten, et al., 2014), as well as to homeless individuals specifically (Biswas-Diener \& Diener, 2006; Johnstone et al., 2016).

Youth further mentioned the importance of self-care and ensuring that their basic needs (e.g., food, sleep, personal hygiene) are met on a regular basis. Resources for selfcare can be provided by external supports, such as social support systems and homeless service centers. Making sure that these resources are both available and easily accessible could greatly impact the well-being of homeless youth. However, it is also important to consider how to promote the development of a self-care mentality among homeless youth, as well as how to effectively support them in autonomously engaging in the selfcare that is necessary as a foundation to their other pursuits (e.g., attending a job interview, going to school, engaging in recreational activities).

Given the importance of both autonomy and empowerment in bolstering the psychological well-being of homeless youth, a simple yet far-reaching goal for service center programs and interventions should be finding ways to support youth in gaining control over their own lives in the form of self-care. For example, service centers could provide the physical resources and space needed for youth to engage in self-care (e.g., 
assistance arranging a place to sleep, personal hygiene, food, etc.). Targeted interventions could then engage youth in discussions about what self-care means to them, why it is important, and small steps they could take to implement self-care routines into their days that promote both their present and long-term well-being, while also serving as a foundation to the other goals they are striving toward. This could be particularly beneficial for youth who struggle with taking care of themselves as they navigate the mental-emotional ups and downs of homelessness while simultaneously striving to become independent, self-sufficient young adults.

The other thematic categories of open-ended responses suggest other factors that also contribute to the well-being of youth experiencing homelessness that may be related to the intrapersonal and social-contextual predictors assessed in the quantitative analyses. For example, some of the responses that fell into the Personal Outlook category were indicative of maintaining optimism in the face of adversity; and items that fell into the categories of Sense of Purpose and Responsibility, Self-Expression, and Learning or Growth could all be related to empowerment.

Furthermore, some of the categories suggest the importance of non-psychological factors, such as critical resources, for well-being. Mentions of service center support and having employment were often discussed in conjunction with physical resources that youth needed to maintain their well-being. Moreover, the service center where this research was conducted offers recreational activities, opportunities for self-expression and personal growth, vocational training, and specific forms of social support that could all be categorized as Organizational factors that contribute to youth's well-being. Future 
research could examine more closely and thoroughly the importance of these organizational factors and resources to the well-being of youth experiencing homelessness.

\section{Limitations}

Several study limitations should be addressed and considered in future research with youth experiencing homelessness. First, generalizability in this study is limited by 1) the relatively small sample size, and 2) the fact that data were collected from youth who are engaged in service use. Thus, findings may not generalize to youth who are homeless but who are not currently utilizing services. Further, those who elected to participate in the study may differ from those who chose not to participate. Moreover, these data were collected during the summer months - a time when the mild weather makes street dwelling somewhat less challenging than during rainy winter months and may keep youth from accessing services as frequently. The experiences of homeless youth from winter to summer may vary, and future research should consider seasonal challenges when studying the well-being of homeless youth. Finally, the limited geographic context may make it difficult to generalize results to other regions or to non-urban areas, although experiences of well-being and factors that are related to well-being are likely quite consistent across settings.

A second major limitation is that correlational cross-sectional analyses cannot determine causality, and thus caution should be taken when interpreting findings. It is quite possible that other factors that were not directly measured in this study exist and interact in complex ways to explain differences in psychological well-being. It is also 
possible that the directionality between well-being and the intrapersonal and socialcontextual predictors may be reversed. For example, youth who have higher levels of well-being may be more likely to seek out opportunities for cultivating social support and sense of community. It is likely that the intrapersonal and social-contextual factors examined interact in a cyclical way with psychological well-being, such that they may promote well-being, while increased well-being can in turn promote the further development of those factors. Longitudinal studies are needed to further understand the direction of effects between variables and their potential interactions. However, this initial cross-sectional, correlational study provides beneficial information about factors that may contribute to the well-being of homeless youth, which can inform larger-scale studies in the future.

A third limitation is the possibility for response bias due to the fact that all data was self-reported by youth. Aside from the potential for fatigue, reactivity, and the order of the measures to have influenced results, participants may have felt pressured to manage their self-presentation, and thus may have under-reported negative experiences and over-reported positive experiences, or the reverse. Further, although efforts were made to ensure that participants knew that their identities and responses would be kept confidential, and that their responses would not be shared with service staff, it is possible that participants were concerned that answering openly and honestly about their wellbeing and related factors could impact their receipt of services. All efforts were taken to minimize these concerns, and also to provide resources to youth in the event that any of the questions become distressing for them. 
Aside from these more general limitations, a few methodological considerations arose during the study that should be noted. First, shortly after data collection began, the question asking youth about their racial background was changed. The purpose of asking about racial background was to understand how the experience of being marginalized by race might relate to the outcome variable. Initially, youth were asked their racial background and given a list of options from which to choose. It was noted that many participants were misunderstanding the question and confusing race with ethnic background or nationality. Further, many youth who would not be expected to be marginalized based exclusively on race were identifying with a marginalized race. For example, youth who would most likely be identified and treated as white based on their phenotypic appearance were stating that they were multiracial based on speculation that they may have Native American ancestry or because they have ancestors who immigrated to America from Ireland. Because of these issues, several changes were made to the question about participant race. First, the item was changed to not include the list of racial categories and was instead stated as an open-ended question. Second, if youth reported an ethnicity or nationality instead of a race, we explained to them the difference and asked the question again. Finally, if youth stated being small percentages of multiple races, we asked them to choose which race they primarily identified with. Because this problem was noticed early on in the data collection phase, all data were retained. However, the demographics of this sample may not be representative of homeless youth in this region, and the problems encountered may have contributed to the non-significant relationship between race and psychological well-being in this sample. 
These methodological issues pertaining to how participants' racial background was measured and recorded could have influenced the analyses examining associations between psychological well-being and race. Future studies with homeless youth should carefully consider how race is asked about in self-report surveys in order to determine whether identification with a marginalized racial group is associated with well-being outcomes. For example, it may be advisable to ask youth if they identify as a person of color rather than constraining their responses to the racial categories commonly used by the United States Census Bureau. Future studies should also engage youth in discussions about how they understand issues surrounding racial identity and its impact on their experiences as homeless youth.

Another potential methodological limitation concerns the measure of social support used in this study. This social support measure did not limit the number of supports that youth could state in any given category. Results suggested that data for this variable were highly skewed, likely due to several participants who reported a very high number of individuals they could turn to for support. Because the skew and kurtosis of this variable were still within an acceptable range of values according to less conservative recommendations (Kline, 2011), it was determined that the data should reflect youth's perspectives and experiences, and thus outliers were not removed, and the variable was left untransformed. However, future studies should consider using more standardized measures of social support (e.g., the previously referenced Social Support Questionnaire by Sarason and colleagues) or refining questions to make sure that only the most important or consistent supports are reported (for example, by asking participants to 
identify supports by name or initials, or by specifying that only the closest supports should be reported).

\section{Future Directions}

The findings and limitations of this study inform numerous future directions for research. First, replication research is needed to determine whether similar findings are observed among samples of youth experiencing homelessness in different locations, with youth who are not engaged in service centers, and with youth from other diverse backgrounds that may not be reflected here. Moreover, future research with homeless youth should incorporate more participatory approaches to research. For example, asking youth about their perspectives of what is important to measure for their well-being could inform new measures that more accurately reflect the developmental stage of this age group and the components of well-being that are a priority to them. Youth could also be presented with the psychological well-being scale items and/or the six components of the psychological well-being theoretical framework and engaged in a critical discussion of what is most relevant to them and how they would change the measure to more accurately reflect their experiences. Qualitative findings from this study also suggest a range of other factors (e.g., self-care, recreational activities) that should be considered in future research with homeless youth, and which may inform the revision of current wellbeing measures or the development of new measures.

Similar activities could also be conducted with the other constructs measured in this study. For example, focus groups with homeless youth regarding sense of community could be conducted in order to understand 1) which communities youth identify with, and 
2) whether or not identification with the homeless youth community benefits their shortand long-term well-being. Critical discussion with youth could shed light on the components of the sense of community construct that are most meaningful for homeless youth, while also pointing to new ways of administering sense of community surveys to more accurately capture the community experiences of homeless youth. As was discussed previously, it is particularly important for future studies to be explicit about the reference community that youth should be thinking about when responding to questions about sense of community. This can be determined beforehand by researchers, or by asking youth to write in or name the community that is most important to them and answer the questions with this reference community in mind. This would provide a more nuanced understanding of the relationship between sense of community and psychological wellbeing by allowing researchers to examine whether a stronger bond with particular physical or relational communities is more or less beneficial to psychological well-being among homeless youth.

A final consideration for future research is examining how the intrapersonal and social-contextual factors assessed in this study may contribute to longer-term resilience and psychological well-being. During times of adversity, youth may not experience high levels of well-being. And even if they do report high levels of well-being, the stress of the adversity may have a negative impact on their well-being in the long term. However, that adversity (such as experiencing homelessness or other traumatic life events) may promote the development of personal capacities that support the resilience and long-term wellbeing of youth. For example, the stressors and hardships that come with homelessness 
could promote the development of a certain level of autonomy and personal growth that they may not have emerged otherwise. Longitudinal research is needed that examines the conditions under which homeless youth may experience these "steeling" effects (Rutter, 2012), and ways that service centers can best promote the development of such capacities. A greater understanding of the risk factors that may contribute to negative long-term outcomes after experiencing adversity (e.g., hyperarousal and sensitization to future stress; Rutter, 2012) is also needed in order to prevent potentially dire mental and physical health outcomes for youth experiencing homelessness.

Future studies should also focus on additional risk and protective factors that expand upon the current investigation. In particular, characteristics of personal strength and resilience, which have been found to be associated with well-being, have also been cited by homeless youth as being important to their survival on the streets. Some of these potential protective factors include goal orientation (Kidd \& Shahar, 2008; Usborne, Lydon, \& Taylor, 2009), spirituality (Bender et al., 2007; Kidd, 2003; Rew \& Horner, 2003), and non-conformity (Bender et al., 2007; Kidd, 2003; Lindsay et al., 2000; Rew \& Horner, 2003). Including all of these factors was beyond the scope of the current research, and future studies should address how these characteristics may relate to psychological well-being among homeless youth. Additionally, future research should consider the complex interactions between predictors of well-being operating at different levels of analysis that either support or impede youth's efforts to transition out of homelessness. 


\section{Conclusion}

In sum, the results of this study expand our understanding of psychological wellbeing among youth who experience homelessness. Individual-level factors such as selfesteem, psychological distress, and self-care appear to be particularly important to wellbeing, but the influence of social contextual factors such as social support and empowerment must also be considered. Study findings can inform prevention, healthpromotion, and intervention programs that aim to help youth transition to more stable and secure living situations and prevent them from experiencing homelessness as adults. Moreover, findings can help to clarify where service centers can improve their efforts to enhance the psychological well-being of homeless youth. Assisting service centers to better understand the well-being of homeless youth can promote services that utilize the strengths and values of youth while also recognizing the unique challenges and needs that must be addressed as youth work to transition out of homelessness. 
Tables

Table 1.

Descriptive Statistics

\begin{tabular}{lcccccccccc}
\hline \multicolumn{1}{c}{ Measure } & $\mathrm{N}$ & Min & Max & Mean & SD & Statistic & SE & Statistic & SE \\
\hline Psychological & & & & & & & & & & \multicolumn{2}{c}{ Kkewness } \\
Well-Being & 100 & 2.44 & 5.78 & 4.39 & 0.64 & -0.39 & 0.24 & -0.08 & 0.48 \\
Optimism & 100 & 1.00 & 5 & 3.31 & 0.74 & -0.39 & 0.24 & 0.42 & 0.48 \\
Self-Esteem & 100 & 1.30 & 4 & 2.93 & 0.56 & -0.42 & 0.24 & 0.29 & 0.48 \\
Psychological & & & & & & & & & \\
Distress & 100 & 1.00 & 5 & 2.72 & 0.80 & 0.34 & 0.24 & -0.34 & 0.48 \\
Loneliness & 100 & 1.00 & 4 & 2.60 & 0.76 & -0.13 & 0.24 & -0.68 & 0.48 \\
Empowerment & 100 & 1.82 & 5 & 3.71 & 0.56 & -0.65 & 0.24 & 1.30 & 0.48 \\
Sense of & & & & & & & & & \\
Community & 100 & 0.42 & 3 & 1.82 & 0.53 & -0.04 & 0.24 & -0.06 & 0.48 \\
Social Support & 100 & 0.00 & 126.67 & 21.06 & 23.60 & 2.77 & 0.24 & 8.61 & 0.48 \\
\hline
\end{tabular}


Table 2.

Demographic Percentages

\begin{tabular}{lc}
\hline Gender & Percent \\
\hline Male & 68 \\
Female & 26 \\
Transgender & 3 \\
Non-binary & 2 \\
Gender fluid & 1 \\
\hline Sexual Orientation & Percent \\
\hline Heterosexual & 67 \\
Bisexual & 18 \\
Gay & 3 \\
Other & 12 \\
\hline Racial Background & Percent \\
\hline White & 52 \\
Black & 15 \\
Latino & 6 \\
Native Hawaiian or & 1 \\
other Pacific Islander & 1 \\
Asian & 9 \\
Multiracial & \\
Other & 16 \\
\hline
\end{tabular}




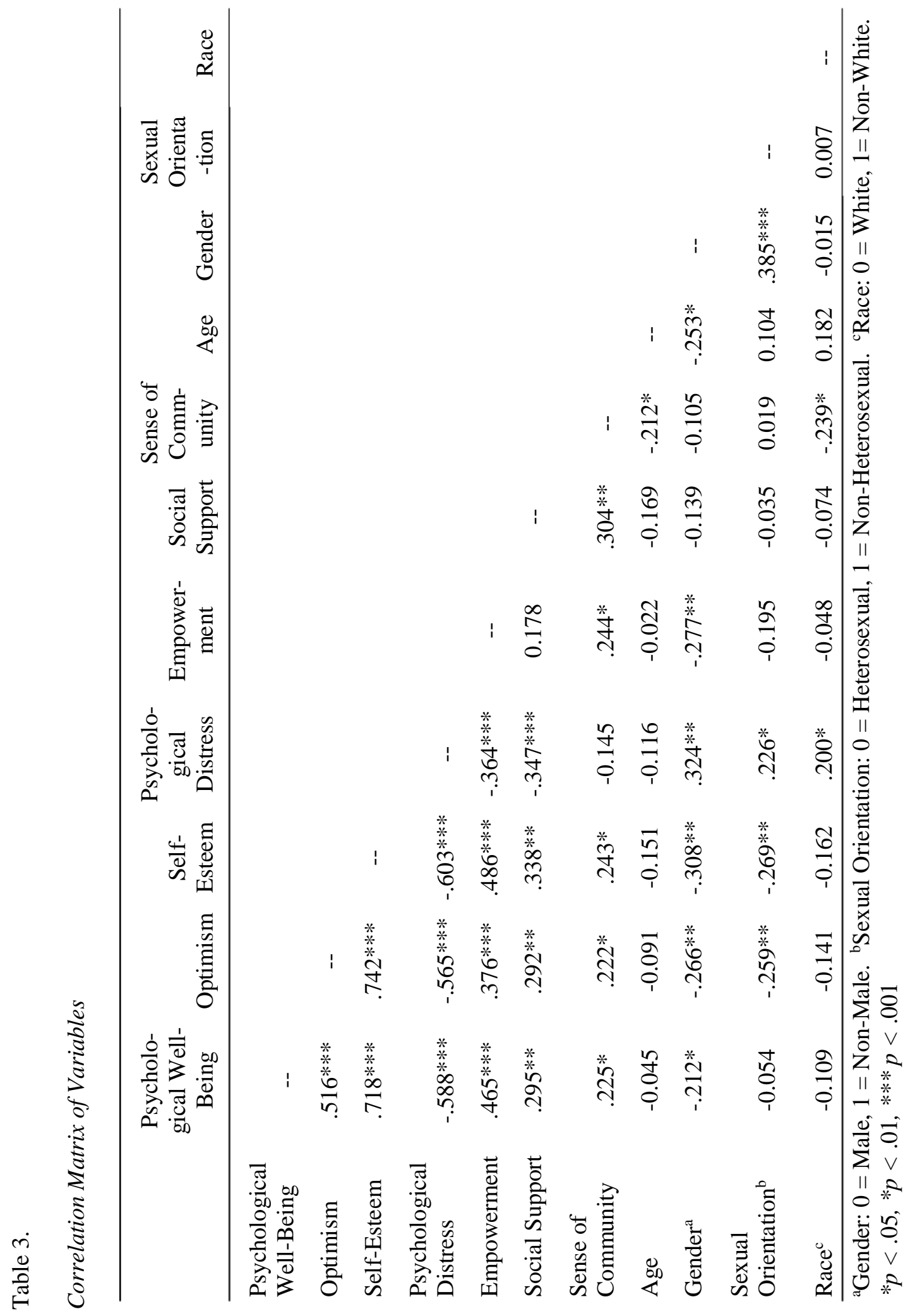


Table 4.

Linear Regression of Intrapersonal Variables Predicting Psychological Well-Being

\begin{tabular}{|c|c|c|c|c|c|}
\hline \multirow{2}{*}{ Variable } & \multicolumn{3}{|c|}{ Model 1} & \multirow{2}{*}{$\mathrm{t}$} & \multirow{2}{*}{$\mathrm{p}$} \\
\hline & B & $\mathrm{SE}$ & Beta & & \\
\hline (Constant) & 3.09 & .448 & & 6.896 & .000 \\
\hline Gender & .066 & .100 & .048 & .661 & .51 \\
\hline Self-Esteem & .746 & .125 & .647 & 5.98 & .000 \\
\hline $\begin{array}{l}\text { Psychological } \\
\text { Distress }\end{array}$ & -.22 & .071 & -.273 & -3.082 & .003 \\
\hline Optimism & -.092 & .090 & -.106 & -1.016 & .312 \\
\hline
\end{tabular}

$R=.749, R^{2}=.516, p<.001$ 
Table 5.

Linear Regression of Social-Contextual Variables Predicting Psychological Well-Being

\begin{tabular}{|c|c|c|c|c|c|}
\hline \multirow{2}{*}{ Variable } & \multicolumn{3}{|c|}{ Model 1} & \multirow{2}{*}{$\mathrm{t}$} & \multirow{2}{*}{$\mathrm{p}$} \\
\hline & B & SE & $\beta$ & & \\
\hline (Constant) & 2.495 & .421 & & 5.924 & .000 \\
\hline Gender & -.094 & .126 & -.068 & -.745 & .458 \\
\hline Empowerment & .453 & .108 & .396 & 4.212 & .000 \\
\hline SOC & .075 & .114 & .061 & .652 & .516 \\
\hline Social Support & .005 & .003 & 196 & 2.11 & .038 \\
\hline
\end{tabular}

$R=.52, R^{2}=.27, p<.001$ 
Table 6.

Hierarchical Linear Regression of Intrapersonal and Social-Contextual Variables Predicting Psychological Well-Being

\begin{tabular}{lccccc}
\hline \multicolumn{1}{c}{ Variable } & $\mathrm{B}$ & $\mathrm{SE}$ & $\beta$ & $\mathrm{R}^{2}$ & $\Delta \mathrm{R}^{2}$ \\
\hline Block 1 & & & & .045 & $.045^{*}$ \\
$\quad$ Constant) & 4.489 & .077 & & & \\
$\quad$ Gender & -.291 & .136 & $-.212^{*}$ & & \\
Block 2 & & & & .561 & $.516^{* * *}$ \\
$\quad$ Constant) & 3.09 & .448 & & & \\
Gender & .066 & .100 & .048 & & \\
Self-Esteem & .746 & .125 & $.647^{* * *}$ & & \\
Psychological & & & & & \\
Distress & -.22 & .071 & $-.273^{* *}$ & & \\
Optimism & -.092 & .090 & -.106 & & \\
Block 3 & & & & .577 & \\
$\quad$ Constant) & 2.615 & .514 & & & \\
Gender & .091 & .101 & .066 & & \\
Self-Esteem & .675 & .131 & $.585^{* * *}$ & & \\
Psychological & & & & & \\
Distress & -.210 & .073 & $-.261^{* *}$ & & \\
Optimism & -.095 & .090 & -.110 & & \\
Empowerment & .152 & .091 & .133 & \\
SOC & .049 & .089 & .040 & \\
Social Support & .000 & .002 & .012 & \\
\hline$* p<$.05, ** $p .01, * * * p<.001$ & & & & \\
\end{tabular}


Table 7.

Thematic Categories for the Open-Ended Well-being Question

\begin{tabular}{|c|c|c|c|}
\hline Thematic Category & Frequency & $\begin{array}{l}\text { Number of } \\
\text { Participants }\end{array}$ & Example \\
\hline Social Support & 88 & 62 & $\begin{array}{l}\text { "Friends have helped a lot in this } \\
\text { situation" }\end{array}$ \\
\hline Self-Care & 37 & 24 & "Exercise and healthy choices" \\
\hline Personal Outlook & 32 & 23 & "Self-motivation not to give up" \\
\hline $\begin{array}{l}\text { Recreational } \\
\text { Activities }\end{array}$ & 29 & 20 & "Reading", "listening to music" \\
\hline Service Center(s) & 26 & 25 & "Service center staff and youth" \\
\hline $\begin{array}{l}\text { Sense of Purpose } \\
\text { and Responsibility }\end{array}$ & 12 & 11 & $\begin{array}{l}\text { "Knowing that they [my kids] } \\
\text { look up to me for love and } \\
\text { support" }\end{array}$ \\
\hline $\begin{array}{l}\text { Learning or } \\
\text { Growth }\end{array}$ & 8 & 7 & "Being in school" \\
\hline Self-Expression & 7 & 6 & $\begin{array}{l}\text { "Being able to express myself } \\
\text { artistically" }\end{array}$ \\
\hline $\begin{array}{l}\text { Vocational } \\
\text { Activities }\end{array}$ & 7 & 7 & "Working at p:ear (barista)" \\
\hline Having Goals & 6 & 6 & "Having plans for future" \\
\hline Spiritual Beliefs & 3 & 3 & "Belief in a higher power" \\
\hline
\end{tabular}


Figures

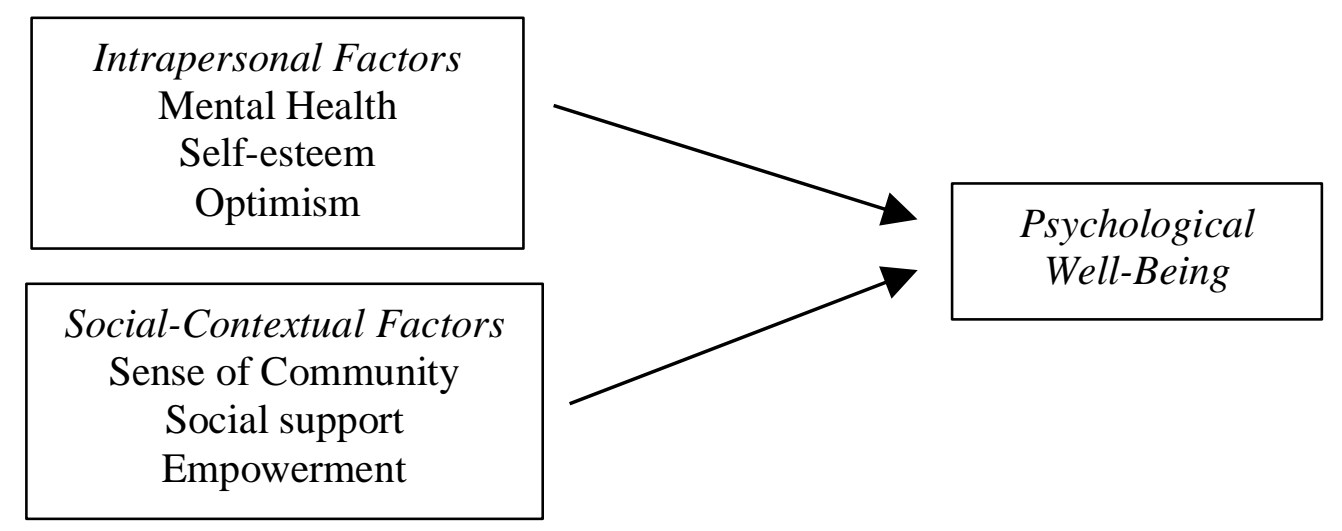

Figure 1. Well-being predicted by intrapersonal and social-contextual factors. 


\section{References}

Adams, G. R., Munro, B., Doherty-Poirer, M., Munro, G., Petersen, A. R., \& Edwards, J. (2001). Diffuse-avoidance, normative, and informational identity styles: Using identity theory to predict maladjustment. Identity, 1, 307-320.

Allan, T. H., \& Allan, K. H. (1971). Sensitivity for community leaders. Proceedings of the 79th Annual Convention of the American Psychological Association, 6, 577570.

Andrews, B., \& Brown, G. W. (1995). Stability and change in low self-esteem: The role of psychosocial factors. Psychological Medicine, 25(01), 23-31.

Annual Homeless Assessment Report to Congress. (2015). Retrieved from: https://www.hudexchange.info/onecpd/assets/File/2015-AHAR-Part-2-Section4.pdf

Antonucci, T. C. (1985). Personal characteristics, social support, and social behavior. In R. H. Binstock, \& E. Shanas (Eds.), Handbook of Aging and the Social Sciences (pp. 94-128). New York: Van Nostrand-Reinhold.

Arnett, J. J. (2004). Emerging Adulthood: The Winding Road from the Late Teens Through the Twenties. Oxford: Oxford University Press.

Barczyk, A. N., Thompson, S. J., \& Rew, L. (2014). The impact of psychosocial factors on subjective well-being among homeless young adults. Health and Social Work, 39(3), 172-180. 
Baumeister, R. F., Campbell, J. D., Krueger, J. I., \& Vohs, K. D. (2003). Does high selfesteem cause better performance, interpersonal success, happiness, or healthier lifestyles? Psychological Science in the Public Interest, 4(1), 1-44.

Bender, K., Thompson, S., McManus, H., Lantry, J., \& Flynn, P. (2007). Capacity for survival: Exploring strengths of homeless street youth. Child and Youth Care Forum, 36(1), 25-42.

Berg, B.L. (2004). Qualitative Research for the Social Sciences, 5th ed. Boston: Pearson.

Berry, W. D., \& Feldman, S. (1985). Multiple Regression in Practice (Quantitative Applications in the Social Sciences). Thousand Oaks, CA: SAGE Publications.

Biswas-Diener, R., \& Diener, E. (2006). The subjective well-being of the homeless, and lessons for happiness. Social Indicators Research, 76, 185-205.

Black, R. A., Serowik, K. L., \& Rosen, M. I. (2009). Associations between impulsivity and high risk sexual behaviors in dually diagnosed outpatients. American Journal of Drug and Alcohol Abuse, 35(5), 325-328.

Blakemore, S. J., \& Choudhury, S. (2006). Development of the adolescent brain: implications for executive function and social cognition. Journal of Child Psychology and Psychiatry, 47(3-4), 296-312.

Boyatzis, R. (1998). Transforming Qualitative Information: Thematic Analysis and Code Development. Thousand Oaks, CA: Sage.

Braun, V., \& Clarke, V. (2006). Using thematic analysis in psychology. Qualitative Research in Psychology, 3(2), 77-101.

Brodsky, A. E. (1996). Resilient single mothers in risky neighborhoods: Negative 
psychological sense of community. Journal of Community Psychology, 24(4), $347-363$.

Bronfenbrenner, U. (1979). The Ecology of Human Development. Cambridge, MA: Harvard University Press.

Brown, J.D., Marshall, M. A. (2001). Self-esteem and emotion: Some thoughts about feelings. Personality and Social Psychology Bulletin, 27(5), 575-584.

Bryk, A., Sebrig, P. B., Allensworth, E., Luppesca, S., \& Easton, J. Q. (2010). Organizing Schools for Improvement: Lessons from Chicago. Chicago, IL: University of Chicago Press.

Buckner J. C., Bassuk E. L., Weinreb L. F. (2001). Predictors of academic achievement among homeless and low-income housed children. Journal of School Psychology, $39,45-69$.

Burns, R. A., \& Machin, M. A. (2010). Identifying gender differences in the independent effects of personality and psychological well-being on two broad affect components of subjective well-being. Personality and Individual Differences, 48 , 22-27.

Castellow, J., Kloos, B., \& Townley, G. (2015). Previous homelessness as a risk factor for recovery from serious mental illnesses. Community Mental Health Journal, 51(6), 674-684.

Carver, C. S., \& Gaines, J. G. (1987). Optimism, pessimism, and postpartum depression. Cognitive Therapy and Research, 11, 449-462.

Carver, C. S., Scheier, M. F., \& Segerstrom, S. C. (2010). Optimism. Clinical Psychology 
Review, 30(7), 879-889.

Chang, E. C., \& Sanna, L. J. (2001). Optimism, pessimism, and positive and negative affectivity in middle-aged adults: A test of a cognitive —affective model of psychological adjustment. Psychology and Aging, 16, 524-531.

Chavis, D. M., Lee, K. S., \& Acosta, J. D. (2008). The Sense of Community Index (SCI) Revised: The Reliability and Validity of the SCI-2. Paper presented at the 2nd international Community Psychology Conference, Lisboa, Portugal.

Chavis, D.M., \& Wandersman, A. (1990). Sense of community in the urban environment: A catalyst for participation and community development. American Journal of Community Psychology, 18, 55-81.

Chipuer, H. M., \& Pretty, G. M. (1999). A review of the sense of community index: Current uses, factor structure, reliability, and further development. Journal of Community Psychology, 27(6), 643-658.

Chipuer, H. M., Bramston, P., \& Pretty, G. (2003). Determinants of subjective quality of life among rural adolescents: A developmental perspective. Social Indicators Research, 61(1), 79-95.

Christiani, A., Hudson, A. L., Nyamathi, A., Mutere, M., \& Sweat, J. (2008). Attitudes of Homeless and Drug-Using Youth Regarding Barriers and Facilitators in Delivery of Quality and Culturally Sensitive Health Care. Journal of Child and Adolescent Psychiatric Nursing, 21(3), 154-163. 
Cook, S. W. (1970). Motives in conceptual analysis of attitude related behavior. In W. J. Arnold \& D. Levine (Eds.), Proceedings of the Nebraska Symposium on Motivation. Lincoln, NE: University of Nebraska Press.

Cleverley, K., \& Kidd, S. A. (2011). Resilience and suicidality among homeless youth. Journal of Adolescence, 34(5), 1049-1054.

Coates, J., \& McKenzie-Mohr, S. (2010). Out of the frying pan, into the fire: Trauma in the lives of homeless youth prior to and during homelessness. Journal of Sociology and Social Welfare, 37(65).

Cochran, B.N., Stewart, A.J., Ginzler, J.A., \& Cauce, A.M. (2002). Challenges faced by homeless sexual minorities: Comparison of gay, lesbian, bisexual, and transgender homeless adolescents with their heterosexual counterparts. American Journal of Public Health, 92, 773-777.

Cohen, S. (1988). Psychosocial models of the role of social support in the etiology of physical disease. Health Psychology, 7, 269-297.

Cohen, P., Kasen, S., Chen, H., Hartmark, C., \& Gordon, K. (2003). Variations in patterns of developmental transitions in the emerging adulthood period. Developmental Psychology, 39, 657-669.

Cohen, S., \& Wills, T. A. (1985). Stress, Social Support, and the Buffering Hypothesis. Psychological Bulletin, 98(2), 310-357.

Craney, T. A., Surles, J. G. (2002). Model-dependent variance inflation factor cutoff values. Quality Engineering, 14(3), 391-403. 
Davidson, W. B., \& Cotter, P. R. (1991). The relationship between sense of community and subjective well-being: A first look. Journal of Community Psychology, 19, 246-253.

Deci, E. L., \& Ryan, R. M. (2008). Hedonia, eudaimonia, and well-being: An introduction. Journal of Happiness Studies, 9, 1-11.

Desai, R.A., Liu-Mares, W., Dausey, D.J., Rosenheck, R.A. (2003). Suicidal ideation and suicide attempts in a sample of homeless people with mental illness. Journal of Nervous Mental Disorders, 191, 365-371.

Diener, E. (2009). Assessing Well-Being: The Collected Works of Ed Diener. Dordrecht Heidelberg London New York: Springer.

Diener, E., \& Diener, M. (1993). Self-esteem and life satisfaction across 31 countries. Sixth Meeting of the International Society for the Study of Individual Differences, Baltimore.

Diener, E., Diener, M. (1995). Cross-cultural correlates of life satisfaction and selfesteem. Journal of Personality and Social Psychology: Personality Processes and Individual Differences, 68(4), 653-663.

Diener, E., Emmons, R. A., Larsen, R. J., \& Griffin, S. (1985). The satisfaction with life scale. Journal of Personality Assessment, 49, 71-75.

Diener, E., Oishi, S., \& Lucas, R. E. (2003). Personality, culture, and subjective wellbeing: emotional and cognitive evaluations of life. Annual Review of Psychology, $54,403-425$. 
Diener, E., Scollon, C. N., \& Lucas, R. E. (2003). The evolving concept of subjective well-being: The multifaceted nature of happiness. Advances in Cell Aging and Gerontology, 15, 187-219.

Diener, E., \& Seligman, M. E. P. (2004). Beyond money: Toward an economy of wellbeing. Science in the Public Interest, 5(1), 1-31.

Dishion, T., \& Connell, A. (2006). Adolescents"' resilience as a self-regulatory process: Promising themes for linking intervention with developmental science. Annals New York Academy of Sciences, 1094, 125-138.

Dolan, P., Peasgood, T., \& White, M. (2008). Do we really know what makes us happy? A review of the economic literature on the factors associated with subjective wellbeing. Journal of Economic Psychology, 29, 94-122.

Durso, L. E., \& Gates, G. J. (2012). Serving Our Youth: Findings from a National Survey of Service Providers Working with Lesbian, Gay, Bisexual and Transgender Youth who are Homeless or at Risk of Becoming Homeless. Los Angeles, CA: The Williams Institute with True Colors Fund and the Palette Fund.

Edidin, J. P., Ganim, Z., Hunter, S. J., \& Karnik, N. S. (2012). The mental and physical health of homeless youth: A literature review. Child Psychiatry and Human Development, 43(3), 354-375.

Eid, M., \& Diener, E. (2004). Global judgments of subjective well-being: situational variability and long-term stability. Social Indicators Research, 65, 245-277.

Erikson, E. H. (1950). Childhood and Society. New York: W. W. Norton \& Company. 
Erwin, R. (2014). Adolescent development. Desktop Guide to Quality Practice for Working with Youth in Confinement. National Partnership for Juvenile Services and Office of Juvenile Justice and Delinquency Prevention. https://info.nicic.gov/dtg/node/10.

Evans, S. D. (2007). Youth sense of community: Voice and power in community contexts. Journal of Community Psychology, 35(6), 693-709.

Fantuzzo, J., \& Perlman, S. (2007). The unique impact of out-of-home placement and the mediating effects of child maltreatment and homelessness on early school success. Children and Youth Services Review, 29(7), 941-960.

Farrington, A., \& Robinson, W. P. (1999). Homelessness and strategies of identity maintenance: A participant observation study. Journal of Community and Applied Social Psychology, 9, 175-194.

Felitti, V. J., Anda, R. F., Norenberg, D., Williamson, D. F., Spitz, A. M., \& Edwards, V. (1998). Relationship of childhood abuse and household dysfunction to many of the leading courses of death in adults. American Journal of Preventive Medicine, $14,245-258$.

Ferguson, K. M., Kim, M. A., \& McCoy, S. (2011). Enhancing empowerment and leadership among homeless youth in agency and community settings: A grounded theory approach. Child and Adolescent Social Work Journal, 28, 1-22.

Festinger, L. (1950). Laboratory experiments: The role of group belongingness. In J. G. Miller (Ed.), Experiments in Social Process. New York: McGraw-Hill.

Fischer, P. J., \& Breakey, W. R. (1991). The epidemiology of alcohol, drug, and mental 
disorders among homeless persons. American Psychologist, 46(11), 1115.

Fordyce, M.W. (1988). A review of research on the happiness measures: A sixty second index of happiness and mental health. Social Indicators Research, 20, 355-381.

Flanagan, C. A. (2004). Volunteerism, leadership, political socialization, and civic engagement. In R. M. Lerner \& L. Steinberg (Eds.), Handbook of Adolescent Psychology (pp. 721-746). New York: Wiley.

Florin, P., \& Wandersman, A. (1984). Cognitive social learning and participation in community development. American Journal of Community Psychology, 12, 689708.

Friis-Hansen, E., \& Duveskog, D. (2012). The empowerment route to well-being: An analysis of farmer field schools in East Africa. World Development, 40(2), 414427.

George, D., \& Mallery, M. (2010). SPSS for Windows Step by Step: A Simple Guide and Reference, 17.0 update (10a ed.). Boston: Pearson.

Giedd, J. N. (2008). The teen brain: insights from neuroimaging. Journal of Adolescent Health, 42(4), 335-343.

Gracia, E., \& Herrero, J. (2004). Determinants of social integration in the community: An exploratory analysis of personal, interpersonal and situational variables. Journal of Community and Applied Psychology, 14, 1-15.

Gray-Little, B., Williams, V.S.L., \& Hancock, T. D. (1997). An item response theory analysis of the Rosenberg Self-Esteem Scale. Personality and Social Psychology Bulletin, 23, 443-451. 
Grigsby, C., Baumann, D., Gregorich, S.E., \& Roberts-Gray, C. (1990). Disaffiliation to entrenchment: A model for understanding homelessness. Journal of Social Issues, $46,141-156$.

Haber, M. G., \& Toro, P. A. (2009). Parent-adolescent violence and later behavioral health problems among homeless and housed youth. American Journal of Orthopsychiatry, 79(3), 305.

Hackman, D. A., \& Farah, M. J. (2009). Socioeconomic status and the developing brain. Trends in Cognitive Sciences, 13(2), 65-73.

Hatzenbuehler, M. L., McLaughlin, K. A., \& Nolen-Hoeksema, S. (2008). Emotion regulation and internalizing symptoms in a longitudinal study of sexual minority and heterosexual adolescents. Journal of Child Psychology and Psychiatry, and Allied Disciplines, 49(12), 1270-1278.

Helliwell, J. F., \& Putnam, R. (2004). The social context of well-being. Philosophical Transactions of the Royal Society of London. Series B, Biological sciences, 359, $1435-1446$.

Hodgson, K. J., Shelton, K. H., van den Bree, M. B., \& Los, F. J. (2013). Psychopathology in young people experiencing homelessness: a systematic review. American Journal of Public Health, 103(6), e24-e37.

House, J. S., \& Kahn, R. L. (1985). Measures and concepts of social support. In S. Cohen, \& S. L. Syme (Eds.), Social Support and Health (pp. 83-108). New York: Academic Press. 
House, J. S., Landis, K. R., \& Umberson, D. (1988). Social relationships and health. Science, 241, 540-545.

Huberman, M., \& Miles, M.B. (2002). The Qualitative Researcher's Companion. Thousand Oaks, CA: Sage.

Hudson, A. L., Nyamathi, A., Greengold, B., Slagle, A., Koniak-Griffin, D., Khalilifard, F., \& Getzoff, D. (2010). Health-seeking challenges among homeless youth. Nursing research, 59(3), 212.

Huppert, F. A., \& Cooper, C. L. (2014). Wellbeing: A Complete Reference Guide, Interventions, and Policies to Enhance Wellbeing. Hoboken, NJ: John Wiley \& Sons, Inc.

Jetten, J., Haslam, C., Haslam, S. A., Dingle, G., \& Jones, J. M. (2014). How groups affect our health and well-being: The path from theory to policy. Social Issues and Policy Review, 8, 103-130.

Johnson, T. P., Aschkenasy, J. R., Herbers, M. R., \& Gillenwater, S. A. (1996). Selfreported risk factors for AIDS among homeless youth. AIDS Education and Prevention.

Johnstone, M., Jetten, J., Dingle, G. A., Parsell, C., \& Walter, Z. C. (2016). Enhancing well-being of homeless individuals by building group memberships. Journal of Community and Applied Social Psychology, 26, 421-438.

Joiner, T. E. (1995). The price of soliciting and receiving negative feedback: Selfverification theory as a vulnerability to depression theory. Journal of Abnormal Psychology, 104(2), 364. 
Jones, R. M., Ross, C. N., \& Hartmann, B. R. (1992). An investigation of cognitive style and alcohol/work-related problems among naval personnel. Journal of Drug Education, 22, 241-251.

Kahn, R. L., \& Antonucci, T. C. (1980). Convoys over the life course: attachment, roles, and social support. In P. B. Baltes, \& O. Brim (Eds.), Life-span Development and Behavior (pp. 253-286). New York: Academic Press.

Khan, S. I., Hussain, M. I., Parveen, S., Bhuiyan, M. I., Gourab, G., Sarker, G. F., ... Sikder, J. (2009). Living on the Extreme Margin: Social Exclusion of the Transgender Population (Hijra) in Bangladesh. Journal of Health, Population, and Nutrition, 27(4), 441-451.

Kamieniecki, G.W. (2001). Prevalence of psychological distress and psychiatric disorders among homeless youth in Australia: A comparative review. Australia and New Zealand Journal of Psychiatry, 35, 352-358

Karabanow, J. (2006). Becoming a street kid: Exploring the stages of street Me. Journal of Human Behavior in the Social Environment, 13(2), 49-72.

Kessler, R. C., Andrews, G., Colpe, L. J., Hiripi, E., Mroczek, D. K., Normand, S. L., ... \& Zaslavsky, A. M. (2002). Short screening scales to monitor population prevalence and trends in non-specific psychological distress. Psychological Medicine, 32(6), 959-976.

Kessler, R. C., Berglund, P., \& Demler, O., et al. (2005): Lifetime prevalence and age-ofonset distributions of DSM-IV disorders in the National Comorbidity Survey Replication. Archives of General Psychiatry, 62, 593-602. 
Keyes, C. L. M. (2002). The mental health continuum: From languishing to flourishing in life. Journal of Health and Social Behavior, 43(2), 207-222.

Keyes, C. L. M., Shmotkin, D., \& Ryff, C. D. (2002). Optimizing well-being: The empirical encounter of two traditions. Journal of Personality and Social Psychology, 82(6), 1007-1022.

Kidd, S. A. (2003). Street youth: coping and intervention. Child and Adolescent Social Work Journal, 235-261.

Kidd, S. A., \& Carroll, M. R. (2007). Coping and suicidality among homeless youth. Journal of Adolescence, 30(2), 283-296.

Kidd, S. A., \& Davidson, L. (2009). Homeless youth: The need to link research and policy. Finding home: Policy options for addressing homelessness in Canada, 19.

Kidd, S. A., \& Davidson, L. (2007). You have to adapt because you have no other choice: The stories of strength and resilience of 208 homeless youth in New York City and Toronto. Journal of Community Psychology, 35(2), 219-238.

Kidd, S. A., \& Kral, M. J. (2002). Suicide and prostitution among street youth: A qualitative analysis. Adolescence, 37(146), 411.

Kidd, S., \& Shahar, G. (2008). Resilience in homeless youth: the key role of self-esteem. American Journal of Orthopsychiatry, 78(2), 163-172.

Kline, R. (2011). Principles and practice of structural equation modeling (3rd edition). New York: Guilford Press. 
Kong, F., Zhao, J., \& You, X. (2013). Self-esteem as mediator and moderator of the relationship between social support and subjective well-being among Chinese university students. Social Indicators Research, 112(1), 151-161.

Kozloff, N., Cheung, A. H., Ross, L. E., Winer, H., Ierfino, D., Bullock, H., \& Bennett, K. J. (2013). Factors influencing service use among homeless youths with cooccurring disorders. Psychiatric Services, 64(9), 925-928.

Kozloff, N., Stergiopoulos, V., Adair, C. E., Cheung, A. H., Misir, V., Townley, G., ... \& Goering, P. (2016). The Unique Needs of Homeless Youths with Mental Illness: Baseline Findings From a Housing First Trial. Psychiatric Services, 67(10), 10831090.

Krauss, S. E., Collura, J., Zeldin, S., Ortega, A., Abdullah, H., \& Sulaiman, A. H. (2014). Youth-adult partnership: Exploring contributions to empowerment, agency and community connections in Malaysian youth programs. Journal of Youth and Adolescence, 43(9), 1550-1562.

Krieger, T., Hermann, H., Zimmermann, J., Grosse Holtforth, M. (2015). Associations of self-compassion and global self-esteem with positive and negative affect and stress reactivity in daily life: Findings from a smart phone study. Personality and Individual Differences, 87, 288-292.

Lakey, B., \& Lutz, C. J. (1996). Social support and preventive and therapeutic interventions. In: G. R. Pierce, B. R. Sarason, \& I. G. Sarason (Eds.), Handbook of Social Support and the Family (pp. 435-465). New York: Plenum. 
Leary, M. R., \& MacDonald, G. (2003). Individual differences in self-esteem: A review and theoretical integration. In M.R. Leary, J.P. Tangney (Eds.), Handbook of self and identity (pp. 401-418). Guilford Press, New York, NY.

Lehman, A. F. (1983). The well-being of chronic mental patients: Assessing their quality of life. Archives of General Psychiatry, 40(4), 369-373.

Lin, C. C. (2015a). Self-esteem mediates the relationship between dispositional gratitude and well-being. Personality and Individual Differences, 85, 145-148.

Lin, C. C. (2015b). Gratitude and depression in young adults: The mediating role of selfesteem and well-being. Personality and Individual Differences, 87, 30-34.

Lindsay, E.W., Kurtz, D., Jarvis, S., Williams, N. R., \& Nackerud, L. (2000). How runaways and homeless youth navigate troubled waters: personal strengths and resources. Child and Adolescent Social Work Journal, 17, 115-140.

Maccio, E. M., \& Schuler, J. T. (2012). Substance use, self-esteem, and self-efficacy among homeless and runaway youth in New Orleans. Child and Adolescent Social Work Journal, 29(2), 123-136.

Makadon, H.J. (2011). Ending LGBT invisibility in health care: the first step in ensuring equitable care. Cleveland Clinical Journal of Medicine, 78(4), 220-224.

Makikangas, A., \& Kinnunen, U. (2003). Psychosocial work stressors and well-being: Self-esteem and optimism as moderators in a one-year longitudinal sample. Personality and Individual Differences, 35, 537-557.

Mallett, S., Rosenthal, D., \& Keys, D. (2005). Young people, drug use and family conflict: Pathways into homelessness. Journal of Adolescence, 28, 185-199. 
Mann, N., Hosman, C. M. H., Schaalma, H. P., \& deVries, N. K. (2004). Self-esteem in a broad-spectrum approach for mental health promotion. Health Education Research, 19(4), 357-372.

Marshall, G. N., Wortman, C. B., Kusulas, J. W., Hervig, K. L., \& Vickers, R. R. (1992). Distinguishing optimism from pessimism: Relations to fundamental dimensions of mood and personality. Journal of Personality and Social Psychology, 62, $1067-1074$.

Massé, R., Poulin, C., Dassa, C., Lambert, J., Bélair, S., \& Battaglini, A. (1998). The structure of mental health: Higher-order confirmatory factor analyses of psychological distress and well-being measures. Social Indicators Research, 45(13), 475-504.

Mazzoni, D., Cicognani, E., Albanesi, C., \& Zani, B. (2014). Quality of participation experience, sense of community and their impact on young people's social wellbeing. Giornale Italiano di Psicologia, 41(1), 205-228.

McMillan, D. (1976). Sense of community: An attempt at definition. George Peabody College for Teachers, Nashville, TN.

McMillan, D. W., \& Chavis, D. M. (1986). Sense of community: A definition and theory. Journal of Community Psychology, 14(1), 6-23.

Meyer, B. (2001). Coping with severe mental illness: relations of the Brief COPE with symptoms, functioning, and well-being. Journal of Psychopathology and Behavioral Assessment, 23(4), 265-277. 
Moore, J. (2005). Unaccompanied and homeless youth: Review of the literature (19952005). National Centre for Homeless Education.

Morgan, D. L. (1998). Practical strategies for combining qualitative and quantitative methods: Applications to health research. Qualitative Health Research, 8(3), 362376.

Morgan, M. L., Vera, E. M., Gonzales, R. R., Conner, W., Bena Vacek, K., \& Dick Coyle, L. (2011). Subjective well-being in urban adolescents: Interpersonal, individual, and community influences. Youth and Society, 43(2), 609-634.

National Alliance to End Homelessness. (2014). Youth. Available from: http://www.endhomelessness.org/pages/youth [last accessed 14 May 2016].

National Health Care for the Homeless Council. (2008). Child and youth homelessness: 2008 policy statements. Retrieved 12 November 2008, from http://www.nhchc.org/Advocacy/PolicyPapers/Child Youth2008.pdf

Noble, K. G., McCandliss, B. D., \& Farah, M. J. (2007). Socioeconomic gradients predict individual differences in neurocognitive abilities. Developmental Science, 10(4), 464-480.

Nurmi, J., Berzonsky, M. D., Tammi, K., \& Kinney, A. (1997). Identity processing orientation, cognitive and behavioral strategies, and well-being. International Journal of Behavioral Development, 21, 555-570.

Nyamathi, A., Hudson, A., Greengold, B., Slagle, A., Marfisee, M., Khalilifard, F., \& Leake, B. (2010). Correlates of substance use severity among homeless youth. Journal of Child and Adolescent Psychiatric Nursing, 23(4), 214-222. 
Obradović, J., Long, J. D., Cutuli, J. J., Chan, C. K., Hinz, E., Heistad, D., \& Masten, A. S. (2009). Academic achievement of homeless and highly mobile children in an urban school district: Longitudinal evidence on risk, growth, and resilience. Development and psychopathology, 21(2), 493-518.

Parks, R. W., Stevens, R. J., \& Spence, S. A. (2007). A systematic review of cognition in homeless children and adolescents. Journal of the Royal Society of Medicine, 100(1), 46-50.

Peterson, N. A., Peterson, C. H., Agre, L., Christens, B. D., \& Mort, C. M. (2011). Measuring youth empowerment: Validation of a sociopolitical control scale for youth in an urban community context. Journal of Community Psychology, 39(5), $592-605$.

Phillips, T. M., \& Pittman, J. F. (2007). Adolescent psychological well-being by identity style. Journal of Adolescence, 30, 1021-1034.

Pichler, F. (2006). Subjective quality of life of young Europeans: Feeling happy but who knows why? Social Indicators Research, 75, 419-444.

Piliavin, I., Sosin, M., Westerfield, A.H., \& Matsueda, R.L. (1993). The duration of homeless careers: An exploratory study. Social Service Review, 67, 576-598.

Pretty, G. M., Conroy, C., Dugay, J., Fowler, K., \& Williams, D. (1996). Sense of community and its relevance to adolescents of all ages. Journal of Community Psychology, 24(4), 365-379. 
Prezza, M., Amici, M., Roberti, T., \& Tedeschi, G. (2001). Sense of community referred to the whole town: Its relations with neighboring, loneliness, life satisfaction and area of residence. Journal of Community Psychology, 29, 29-52.

Prezza, M., \& Costantini, S. (1998). Sense of community and life satisfaction: Investigation in three different territorial contexts. Journal of Community and Applied Social Psychology, 8(3), 181-194.

Prince-Embury, S., \& Saklofske, D. H. (2013). Resilience in Children, Adolescents, and Adults: Translating Research into Practice. New York: Springer.

Provencher, H. L., \& Keyes, C. L. (2011). Complete mental health recovery: Bridging mental illness with positive mental health. Journal of Public Mental Health, 10(1), 57-69.

Rafferty, Y., Shinn, M., \& Weitzman, B. C. (2004). Academic achievement among formerly homeless adolescents and their continuously housed peers. Journal of School Psychology, 42(3), 179-199.

Ramirez-Valles, J., Garcia, D., Campbell, R. T., Diaz, R. M., \& Heckathorn, D. D. (2008). HIV infection, sexual risk behavior, and substance use among latino gay and bisexual men and transgender persons. American Journal of Public Health, 98(6), 1036-1042.

Rappaport, J. (1987). Terms of empowerment/exemplars of prevention: Toward a theory for community psychology. American Journal of Community Psychology, 15(2), 121-148. 
Reck, J. (2009). Homeless gay and transgender youth of color in San Francisco: "No one likes street kids"-Even in the Castro. Journal of LGBT Youth, 6(2-3), 223-242.

Reeg, B. (2003). The Runaway and Homeless Youth Act and disconnected youth. In J. Levin-Epstein \& M.H. Greenberg MH (Eds.), Leave no youth behind: Opportunities for congress to reach disconnected youth. Washington, DC: Center for Law and Social Policy.

Reid, S., Berman, H., \& Forchuk, C. (2005). Living on the streets in Canada: A feminist narrative study of girls and young women. Issues in Comprehensive Pediatric Nursing, 28(4), 237-256.

Rew, L., \& Horner, S. D. (2003). Personal strengths of homeless adolescents living in a high-risk environment. ANS. Advances in Nursing Science, 26, 90-101.

Robertson, M. J. (1996). Homeless youth on their own. Berkeley, CA: Alcohol Research.

Robertson, M. J., \& Toro, P. A. (1999). Homeless youth: Research, intervention, and policy. In Practical lessons: The 1998 national symposium on homelessness research. Washington, DC: US Department of Housing and Urban Development and US Department of Health and Human Services.

Romer, D., Betancourt, L., Giannetta, J. M., Brodsky, N. L., Farah, M., \& Hurt, H. (2009). Executive cognitive functions and impulsivity as correlates of risk taking and problem behavior in preadolescents. Neuropsychologia, 47(13), 2916-2926.

Rosenberg, M. (1965). Society and the Adolescent Self-Image. Princeton, NJ: Princeton University. 
Rosenberg, M. Schooler, C., Schoenbach, C., \& Rosenberg, F. (1995). Global self-esteem and specific self-esteem: Different concepts, different outcomes. American Sociological Review, 60(1).

Roy, E., Haley, N., Leclerc, P., Sochanski, B., Boudreau, J., \& Boivin, J. (2004). Mortality in a cohort of street youth in Montreal. Journal of the American Medical Association, 292, 569-574.

Royal, M. A., \& Rossi, R. J. (1996). Individual-level correlates of sense of community: Findings from workplace and school. Journal of Community Psychology, 24(4), $395-416$.

Rubin, D. H., Erickson, C. J., San Agustin, M., Cleary, S. D., Allen, J. K., \& Cohen, P. (1996). Cognitive and academic functioning of homeless children compared with housed children. Pediatrics, 97(3), 289-294.

Ryff, C. D. (1989). Happiness is everything, or is it? Explorations on the meaning of psychological well-being. Journal of Personality and Social Psychology, 57, 1069-1081.

Ryff, C. D. (1995). Psychological well-being in adult life. Current Directions in Psychological Science, 4, 99-104.

Ryff, C. D., \& Keyes, C. L. M. (1995). The structure of psychological well-being revisited. Journal of Personality and Social Psychology, 69(4), 719.

Salomonsen-Sautel, S., Van Leeuwen, J. M., Gilroy, C., Boyle, S., Malberg, D., \& Hopfer, C. (2008). Correlates of substance use among homeless youths in eight cities. American Journal on Addictions, 17(3), 224-234. 
Sarason, Levine, Basham, \& Sarason (1983). Assessing social support: The Social Support Questionnaire. Journal of Personality and Social Psychology, 44(1), $127-$ 139.

Sarason, S. B. (1974). The Psychological Sense of Community: Prospects for a Community Psychology. San Francisco: Jossey-Bass.

Scheier, M. F., \& Carver, C. S. (1985). Optimism, coping, and health: assessment and implications of generalized outcome expectancies. Health Psychology, 4, 219247.

Scheier, M. F., Carver, C. S., \& Bridges, M. W. (1994). Distinguishing optimism from neuroticism (and trait anxiety, self-mastery, and self-esteem): A reevaluation of the Life Orientation Test. Journal of Personality and Social Psychology, 67(6), 1063.

Shackelford, T. K. (2001). Self-esteem in marriage. Personality and Individual Differences, 30(3), 371-390.

Sherif, M., White, B. J., \& Harvey, 0. J. (1955). Status in experimentally produced groups. American Journal of Sociology, 60, 310-379.

Slesnick, N., Prestopnik, J. (2005). Dual and multiple diagnosis among substance using runaway youth. American Journal of Drug and Alcohol Abuse, 1, 179-201.

Snow, D.A., \& Anderson, L. (1987). Identity work among the homeless: The verbal construction and avowal of personal identities. American Journal of Sociology, 92, 1336-1371.

Sonn, C. C., \& Fisher, A. T. (1996). Aspirations to community: Community responses to 
rejection. Journal of Community Psychology, 24(4), 4 17-430.

Suslow, T., Roestela, C., Ohrmanna, P., \& Arolta, V. (2003). The experience of basic emotions in schizophrenia with and without affective negative symptoms. Comprehensive Psychiatry, 44(4), 303-310.

Talo, C., Mannarini, T., \& Rochira, A. (2014). Sense of community and community participation: A meta-analytic review. Social Indicators Research, 117, 1-28.

Taylor, S. E., \& Armor, D. A. (1996). Positive illusions and coping with adversity. Journal of Personality, 64, 873-898

Taylor, D. M., Lydon, J. E., Bougie, É., \& Johannesen, K. (2004). "Street Kids": Towards an Understanding of Their Motivational Context. Canadian Journal of Behavioural Science, 36(1), 1.

Teicher, M. H., Polcari, A., Anderson, C. M., Andersen, S. L., Lowen, S. B., \& Navalta, C. P. (2003). Rate dependency revisited: understanding the effects of methylphenidate in children with attention deficit hyperactivity disorder. Journal of Adolescent Psychopharmacology, 13(1), 41-51.

Townley, G., Kloos, B., Green, E. P., \& Franco, M. M. (2011). Reconcilable differences? Human diversity, cultural relativity, and sense of community. American Journal of Community Psychology, 47(1-2), 69-85.

Townley, G., Pearson, L., Lehrwyn, J. M., Prophet, N. T., \& Trauernicht, M. (2016). Using participatory mapping and GIS to examine the activity spaces of homeless youth. American Journal of Community Psychology, 57, 404-414. 
U.S. Census Bureau. (2009). Family status and household relationship of people 15 years and over, by marital status, age, and sex: 2009. Retrieved from http://www.census.gov/popu lation/www/socdemo/hh-fam/cps2009.html

Usborne, E., Lydon, J. E., \& Taylor, D. M. (2009). Goals and social relationships: Windows into the motivation and well-being of "street kids." Journal of Applied Social Psychology, 39, 1057-1082.

Wandersman, A., \& Florin, P. (2000). Citizen participation and community organizations. In J. Rappaport \& E. Seidman (Eds.), Handbook of Community Psychology (pp. 247-272). New York: Plenum.

Wandersman, A., \& Giamartino, G. A. (1980). Community and individual difference characteristics as influences of an initial participation. American Journal of Community Psychology, 8, 211-228.

Watson, D., Suls, J., \& Haig, J. (2002). Global self-esteem in relation to structural models of personality and affectivity. Journal of Personality and Social Psychology, $83(1), 185$.

Weich, S., Brugha, T., King, M., McManus, S., Bebbington, P., Jenkins, R., Cooper, C., McBride, O., Stewart-Brown, S. (2011). Mental well-being and mental illness: Findings from the Adult Psychiatric Morbidity Survey for England 2007. British Journal of Psychiatry, 199(1), 23-28.

White, J. M., \& Jones, R. M. (1996). Identity style of male inmates. Criminal Justice and Behavior, 23, 490-504. 
White, J. M., Montgomery, M. J., Wampler, R. S., \& Fischer, J. L. (2003). Recovery from alcohol or drug abuse: The relationship between identity styles and recovery behaviors. Identity, 3, 325-345.

White, J. M., Wampler, R. S., \& Winn, K. I. (1998). The identity style inventory: A revision with a sixth-grade reading level (ISI-6G). Journal of Adolescent Research, 13, 223-245.

Wilson, W., \& Miller, N. (1961). Shifts in evaluations of participants following intergroup competition. Journal of Abnormal and Social Psychology, 63, 428431.

World Health Organization. (2014). Mental health: A state of well-being. Available online at: http://www.who.int.proxy.lib.pdx.edu/features/factfiles/mental_health/en/

Van Wormer, R. (2003). Homeless youth seeking assistance: A research-based study from Duluth, Minnesota. Child and Youth Care Forum, 32, 89-103.

Whitbeck, L. B., Chen, X., Hoyt, D. R., Tyler, K. A., \& Johnson, K. D. (2004). Mental disorder, subsistence strategies, and victimization among gay, lesbian, and bisexual homeless and runaway adolescents. Journal of Sex Research, 41(4), 329342.

Whitbeck, L. B., Hoyt, D. R., Johnson, K. D., \& Chen, X. (2007). Victimization and posttraumatic stress disorder among runaway and homeless adolescents. Violence and Victims, 22, 721-734. 
Wilkinson, K. P. (1979). Social well-being and community. Community Development, 10(1), 5-16.

Wrate, R., \& McLoughlin, P. (1997). Feeling bad: the troubled lives and health of single young homeless people in Edinburgh. Edinburgh: Lothian Health Authority.

Youniss, J., \& Yates, M. (1999). Youth service and moral-civic identity: A case for everyday morality. Educational Psychology Review, 11(4), 363-378.

Yu, M., North, C. S., LaVesser, P. D., Osborne, V. A., \& Spitznagel, E. L. (2008). A comparison study of psychiatric and behavior disorders and cognitive ability among homeless and housed children. Community Mental Health Journal, 44(1), $1-10$.

Zima, B. T., Wells, K. B., \& Freeman, H. E. (1994). Emotional and behavioral problems and severe academic delays among sheltered homeless children in Los Angeles County. American Journal of Public Health, 84(2), 260-264.

Zimmerman, M., \& Rappaport, J. (1988). Citizen participation, perceived control and psychological empowerment. American Journal of Community Psychology, 5, $725-750$.

Zlotnick, C., Robertson, M.J., \& Lahiff, M. (1999). Getting off the streets: Economic resources and residential exits from homelessness. Journal of Community Psychology, 27, 209-224. 


\section{Appendix}

\section{Measures}

Psychological Well-Being (Ryff \& Keyes, 1995)

The following set of questions deals with how you feel about yourself and your life.

Please remember that there are no right or wrong answers.

\begin{tabular}{|c|c|c|c|c|c|c|}
\hline $\begin{array}{l}\text { Circle the number that best describes } \\
\text { your present agreement or } \\
\text { disagreement with each statement. }\end{array}$ & $\begin{array}{l}\text { Strongly } \\
\text { Disagree }\end{array}$ & $\begin{array}{l}\text { Disagree } \\
\text { Somewhat }\end{array}$ & $\begin{array}{l}\text { Disagree } \\
\text { Slightly }\end{array}$ & $\begin{array}{c}\text { Agree } \\
\text { Slightly }\end{array}$ & $\begin{array}{c}\text { Agree } \\
\text { Somewhat }\end{array}$ & $\begin{array}{c}\text { Strongly } \\
\text { Agree }\end{array}$ \\
\hline $\begin{array}{l}\text { 1. In general, I feel I am in charge of } \\
\text { the situation in which I live. }\end{array}$ & 1 & 2 & 3 & 4 & 5 & 6 \\
\hline $\begin{array}{l}\text { 2. When I look at the story of my } \\
\text { life, I am pleased with how things } \\
\text { have turned out. }\end{array}$ & 1 & 2 & 3 & 4 & 5 & 6 \\
\hline $\begin{array}{l}\text { 3. Maintaining close relationships } \\
\text { has been difficult and frustrating for } \\
\text { me. }\end{array}$ & 1 & 2 & 3 & 4 & 5 & 6 \\
\hline $\begin{array}{l}\text { 4. The demands of everyday life } \\
\text { often get me down. }\end{array}$ & 1 & 2 & 3 & 4 & 5 & 6 \\
\hline $\begin{array}{l}\text { 5. I live life one day at a time and } \\
\text { don't really think about the future. }\end{array}$ & 1 & 2 & 3 & 4 & 5 & 6 \\
\hline $\begin{array}{l}\text { 6. I am quite good at managing the } \\
\text { many responsibilities of my daily } \\
\text { life. }\end{array}$ & 1 & 2 & 3 & 4 & 5 & 6 \\
\hline $\begin{array}{l}\text { 7. I think it is important to have new } \\
\text { experiences that challenge how you } \\
\text { think about yourself and the world. }\end{array}$ & 1 & 2 & 3 & 4 & 5 & 6 \\
\hline $\begin{array}{l}\text { 8. I like most aspects of my } \\
\text { personality. }\end{array}$ & 1 & 2 & 3 & 4 & 5 & 6 \\
\hline $\begin{array}{l}\text { 9. I tend to be influenced by people } \\
\text { with strong opinions. }\end{array}$ & 1 & 2 & 3 & 4 & 5 & 6 \\
\hline $\begin{array}{l}\text { 10. In many ways, I feel } \\
\text { disappointed about my achievements } \\
\text { in life. }\end{array}$ & 1 & 2 & 3 & 4 & 5 & 6 \\
\hline $\begin{array}{l}\text { 11. People would describe me as a } \\
\text { giving person, willing to share my } \\
\text { time with others. }\end{array}$ & 1 & 2 & 3 & 4 & 5 & 6 \\
\hline $\begin{array}{l}\text { 12. I have confidence in my } \\
\text { opinions, even if they are contrary to } \\
\text { the general consensus. }\end{array}$ & 1 & 2 & 3 & 4 & 5 & 6 \\
\hline
\end{tabular}


13. I have not experienced many warm and trusting relationships with 1 2 3

4

5

6 others.

14. Some people wander aimlessly through life, but I am not one of them.

15. I sometimes feel as if I've done all there is to do in life.

16. I gave up trying to make big improvements or changes in my life a long time ago.

17. I judge myself by what I think is important, not by the values of what others think is important.

18. For me, my life has been a continuous process of learning, changing, \& growth

19. What contributes to your overall (open-ended item) well-being in your life currently?

\section{Demographics}

\begin{tabular}{|c|c|c|c|c|c|}
\hline \multicolumn{3}{|c|}{ 1. How do you identify your gender? } & & & \\
\hline \multicolumn{3}{|c|}{ 2. How do you identify your sexual orientation? } & & & \\
\hline \multicolumn{3}{|c|}{ 3. How old are you? } & - & & \\
\hline \multicolumn{6}{|c|}{$\begin{array}{l}\text { 4. Which of the following best describes your racial background (you may select more than one } \\
\text { category): }\end{array}$} \\
\hline White & Black & \multicolumn{2}{|c|}{ Alaskan Native/Native American } & Asian & Other \\
\hline 1 & 2 & \multicolumn{2}{|r|}{3} & 4 & 5 \\
\hline \multicolumn{6}{|c|}{ 4a. If you chose other, please specify: } \\
\hline \multicolumn{3}{|c|}{ 5. How old were you when you first became homeless? } & & & \\
\hline \multicolumn{3}{|c|}{$\begin{array}{l}\text { 6. In your entire life what is the total number of times you } \\
\text { have been homeless? }\end{array}$} & & & \\
\hline \multicolumn{3}{|c|}{$\begin{array}{l}\text { 7. In your entire life what is the total amount of time you } \\
\text { have been homeless? }\end{array}$} & \multicolumn{3}{|l|}{ (years/months) } \\
\hline \multicolumn{3}{|c|}{$\begin{array}{l}\text { 8. Can you briefly describe how you became homeless } \\
\text { this most recent time? }\end{array}$} & & & \\
\hline
\end{tabular}


Psychiatric distress (Kessler et al., 2002)

\begin{tabular}{|l|c|c|c|c|c|}
\hline $\begin{array}{l}\text { During the past } 30 \text { days, about how often did } \\
\text { you feel... }\end{array}$ & $\begin{array}{c}\text { All of } \\
\text { the time }\end{array}$ & $\begin{array}{c}\text { Most of } \\
\text { the time }\end{array}$ & $\begin{array}{c}\text { Some of } \\
\text { the time }\end{array}$ & $\begin{array}{c}\text { A little of } \\
\text { the time }\end{array}$ & $\begin{array}{c}\text { None of } \\
\text { the time }\end{array}$ \\
\hline $\begin{array}{l}\text { a. nervous? } \\
\text { b. hopeless? }\end{array}$ & 1 & 2 & 3 & 4 & 5 \\
\hline c. restless or fidgety? & 1 & 2 & 3 & 4 & 5 \\
\hline d. so depressed that nothing could cheer you up? & 1 & 2 & 3 & 4 & 5 \\
\hline e. that everything was an effort? & 1 & 2 & 3 & 4 & 5 \\
\hline f. worthless? & 1 & 2 & 3 & 4 & 5 \\
\hline
\end{tabular}

Self-Esteem (Rosenberg, 1965)

Below is a list of statements dealing with your general feelings about yourself. Please indicate how strongly you agree or disagree with each statement.

1. On the whole, I am satisfied with myself.

2. At times I think I am no good at all.

3. I feel that I have a number of good qualities.

4. I am able to do things as well as most other people.

5. I feel I do not have much to be proud of.

6. I certainly feel useless at times.

7. I feel that I'm a person of worth, at least on an equal plane with others.

8. I wish I could have more respect for myself.

9. All in all, I am inclined to feel that I am a failure.

10. I take a positive attitude toward myself.

\begin{tabular}{|c|c|c|c|c|}
\hline $\begin{array}{c}\text { Strongly } \\
\text { Agree }\end{array}$ & Agree & Disagree & $\begin{array}{c}\text { Strongly } \\
\text { Disagree }\end{array}$ \\
\hline 1 & 2 & 3 & 4 \\
\hline 1 & 2 & 3 & 4 \\
\hline 1 & 2 & 3 & 4 \\
\hline 1 & 2 & 3 & 4 \\
\hline 1 & 2 & 3 & 4 \\
\hline 1 & 2 & 3 & 4 \\
\hline & 1 & 2 & 3 & 4 \\
\hline
\end{tabular}

Optimism (Carver, Scheier, and Segerstrong, 2010)

\begin{tabular}{|c|c|c|c|c|c|}
\hline $\begin{array}{l}\text { Please indicate how strongly you agree or } \\
\text { disagree with each statement. }\end{array}$ & $\begin{array}{l}\text { Strongly } \\
\text { Agree }\end{array}$ & Agree & $\begin{array}{c}\text { Neither Agree } \\
\text { nor Disagree }\end{array}$ & Disagree & $\begin{array}{l}\text { Strongly } \\
\text { Disagree }\end{array}$ \\
\hline $\begin{array}{l}\text { 1. In uncertain times, I usually expect the } \\
\text { best. }\end{array}$ & 1 & 2 & 3 & 4 & 5 \\
\hline $\begin{array}{l}\text { 2. If something can go wrong for me, it } \\
\text { will. }\end{array}$ & 1 & 2 & 3 & 4 & 5 \\
\hline 3. I'm always optimistic about my future. & 1 & 2 & 3 & 4 & 5 \\
\hline $\begin{array}{l}\text { 4. I hardly ever expect things to go my } \\
\text { way. }\end{array}$ & 1 & 2 & 3 & 4 & 5 \\
\hline
\end{tabular}




\begin{tabular}{|c|c|c|c|c|c|}
\hline $\begin{array}{l}\text { 5. I rarely count on good things happening } \\
\text { to me. }\end{array}$ & 1 & 2 & 3 & 4 & 5 \\
\hline $\begin{array}{l}\text { 6. Overall, I expect more good things to } \\
\text { happen to me than bad. }\end{array}$ & 1 & 2 & 3 & 4 & 5 \\
\hline
\end{tabular}

Sense of Community Index- 2 (SCI-2; Chavis, Lee, \& Acosta, 2008).

Please think about your broader community for these questions, as in Portland, Gresham, etc.

How important is it to you to feel a sense of community with community members?

\begin{tabular}{|c|c|c|c|c|c|}
\hline $\begin{array}{c}\text { Prefer not to be part of this } \\
\text { community }\end{array}$ & $\begin{array}{c}\text { Not important at } \\
\text { all }\end{array}$ & $\begin{array}{c}\text { Not very } \\
\text { important }\end{array}$ & $\begin{array}{c}\text { Somewhat } \\
\text { important }\end{array}$ & Important & $\begin{array}{c}\text { Very } \\
\text { important }\end{array}$ \\
\hline 1 & 2 & 3 & 4 & 5 & 6 \\
\hline
\end{tabular}

How well do each of the following statements represent how you FEEL about this community?

\begin{tabular}{|c|c|c|c|c|}
\hline & not at all & somewhat & mostly & completely \\
\hline $\begin{array}{l}\text { 1. I get important needs of mine met because I am } \\
\text { part of this community }\end{array}$ & 1 & 2 & 3 & 4 \\
\hline 2. Community members and I value the same things & 1 & 2 & 3 & 4 \\
\hline $\begin{array}{l}\text { 3. This community has been successful in getting the } \\
\text { needs of its members met }\end{array}$ & 1 & 2 & 3 & 4 \\
\hline $\begin{array}{l}\text { 4. Being a member of this community makes me feel } \\
\text { good }\end{array}$ & 1 & 2 & 3 & 4 \\
\hline $\begin{array}{l}\text { 5. When I have a problem, I can talk about it with } \\
\text { members of this community }\end{array}$ & 1 & 2 & 3 & 4 \\
\hline $\begin{array}{l}\text { 6. People in this community have similar needs, } \\
\text { priorities, and goals }\end{array}$ & 1 & 2 & 3 & 4 \\
\hline 7. I can trust people in this community & 1 & 2 & 3 & 4 \\
\hline $\begin{array}{l}\text { 8. I can recognize most of the members of this } \\
\text { community }\end{array}$ & 1 & 2 & 3 & 4 \\
\hline 9. Most community members know me & 1 & 2 & 3 & 4 \\
\hline $\begin{array}{l}\text { 10. This community has symbols and expressions of } \\
\text { membership such as clothes, signs, art, architecture, } \\
\text { logos, landmarks, and flags that people can recognize }\end{array}$ & 1 & 2 & 3 & 4 \\
\hline $\begin{array}{l}\text { 11. I put a lot of time and effort into being part of this } \\
\text { community }\end{array}$ & 1 & 2 & 3 & 4 \\
\hline $\begin{array}{l}\text { 12. Being a member of this community is part of my } \\
\text { identity }\end{array}$ & 1 & 2 & 3 & 4 \\
\hline 13. Fitting into this community is important to me & 1 & 2 & 3 & 4 \\
\hline 14. This community can influence other communities & 1 & 2 & 3 & 4 \\
\hline $\begin{array}{l}\text { 15. I care about what other community members } \\
\text { think of me }\end{array}$ & 1 & 2 & 3 & 4 \\
\hline
\end{tabular}




\begin{tabular}{|l|l|l|l|l|}
\hline 16. I have influence over what this community is like & 1 & 2 & 3 & 4 \\
\hline $\begin{array}{l}\text { 17. If there is a problem in this community, members } \\
\text { can get it solved }\end{array}$ & 1 & 2 & 3 & 4 \\
\hline 18. This community has good leaders & 1 & 2 & 3 & 4 \\
\hline $\begin{array}{l}\text { 19. It is very important to me to be part of this } \\
\text { community }\end{array}$ & 1 & 2 & 3 & 4 \\
\hline $\begin{array}{l}\text { 20. I am with other community members a lot and } \\
\text { enjoy being with them }\end{array}$ & 1 & 2 & 3 & 4 \\
\hline $\begin{array}{l}\text { 21. I expect to be part of this community for a long } \\
\text { time }\end{array}$ & 1 & 2 & 3 & 4 \\
\hline $\begin{array}{l}\text { 22. Members of this community have shared } \\
\text { important events together, such as holidays, } \\
\text { celebrations, or disasters }\end{array}$ & 1 & 2 & 3 & 4 \\
\hline \begin{tabular}{l} 
23. I feel hopeful about the future of this community \\
\hline $\begin{array}{l}\text { 24. Members of this community care about each } \\
\text { other }\end{array}$
\end{tabular}$\quad 1$ & 2 & 3 & 4 \\
\hline
\end{tabular}

\section{$\underline{\text { Social support }}$}

How many family members can you turn to for support?

How satisfied are you with your relationship with your family?

\begin{tabular}{|c|c|c|c|c|}
\hline Very Dissatisfied & Dissatisfied & Neither Dissatisfied or Satisfied & Satisfied & Very Satisfied \\
\hline 1 & 2 & 3 & 4 & 5 \\
\hline $\begin{array}{l}\text { How many friends around your age can you turn to for support? } \\
\text { How satisfied are you with your relationships with your friends? }\end{array}$ \\
\hline Very Dissatisfied & Dissatisfied & Neither Dissatisfied or Satisfied & Satisfied & Very Satisfied \\
\hline 1 & 2 & 3 & 4 & 5 \\
\hline $\begin{array}{l}\text { How many other adults can you turn to for support? } \\
\text { How satisfied are you with your relationships with these adults? }\end{array}$ \\
\hline Very Dissatisfied & Dissatisfied & Neither Dissatisfied or Satisfied & Satisfied & Very Satisfied \\
\hline 1 & 2 & 3 & 4 & 5 \\
\hline
\end{tabular}

Empowerment (Peterson et al., 2011)

\begin{tabular}{|l|c|c|c|c|c|}
\hline $\begin{array}{l}\text { Please indicate the extent to which you } \\
\text { agree with each of the following statements: }\end{array}$ & $\begin{array}{c}\text { Strongly } \\
\text { Agree }\end{array}$ & Agree & $\begin{array}{c}\text { Neither Agree } \\
\text { nor Disagree }\end{array}$ & Disagree & $\begin{array}{c}\text { Strongly } \\
\text { Disagree }\end{array}$ \\
\hline I am often a leader in groups & 1 & 2 & 3 & 4 & 5 \\
\hline
\end{tabular}




\begin{tabular}{|c|c|c|c|c|c|}
\hline $\begin{array}{l}\text { I would prefer to be a leader rather than a } \\
\text { follower }\end{array}$ & 1 & 2 & 3 & 4 & 5 \\
\hline $\begin{array}{l}\text { I would rather have a leadership role when } \\
\text { I'm involved in a group project }\end{array}$ & 1 & 2 & 3 & 4 & 5 \\
\hline $\begin{array}{l}\text { I can usually organize people to get things } \\
\text { done }\end{array}$ & 1 & 2 & 3 & 4 & 5 \\
\hline Other people usually follow my ideas & 1 & 2 & 3 & 4 & 5 \\
\hline I find it very easy to talk in front of a group & 1 & 2 & 3 & 4 & 5 \\
\hline $\begin{array}{l}\text { I like to work on solving a problem myself } \\
\text { rather than wait and see if someone else will } \\
\text { deal with it }\end{array}$ & 1 & 2 & 3 & 4 & 5 \\
\hline $\begin{array}{l}\text { I like trying new things that are challenging } \\
\text { to me }\end{array}$ & 1 & 2 & 3 & 4 & 5 \\
\hline $\begin{array}{l}\text { I enjoy participation because I want to have } \\
\text { as much say in my community or school as } \\
\text { possible }\end{array}$ & 1 & 2 & 3 & 4 & 5 \\
\hline $\begin{array}{l}\text { Youth like me can really understand what's } \\
\text { going on with my community or school }\end{array}$ & 1 & 2 & 3 & 4 & 5 \\
\hline $\begin{array}{l}\text { I feel like I have a pretty good } \\
\text { understanding of the important issues which } \\
\text { confront my community or school }\end{array}$ & 1 & 2 & 3 & 4 & 5 \\
\hline $\begin{array}{l}\text { Youth like me have the ability to participate } \\
\text { effectively in community or school activities } \\
\text { and decision making }\end{array}$ & 1 & 2 & 3 & 4 & 5 \\
\hline $\begin{array}{l}\text { My opinion is important because it could } \\
\text { someday make a difference in my } \\
\text { community or school }\end{array}$ & 1 & 2 & 3 & 4 & 5 \\
\hline $\begin{array}{l}\text { There are plenty of ways for youth like me } \\
\text { to have a say in what our community or } \\
\text { school does }\end{array}$ & 1 & 2 & 3 & 4 & 5 \\
\hline $\begin{array}{l}\text { It is important to me that I actively } \\
\text { participate in local youth issues }\end{array}$ & 1 & 2 & 3 & 4 & 5 \\
\hline $\begin{array}{l}\text { Most community or school leaders would } \\
\text { listen to me }\end{array}$ & 1 & 2 & 3 & 4 & 5 \\
\hline $\begin{array}{l}\text { Many local activities are important to } \\
\text { participate in }\end{array}$ & 1 & 2 & 3 & 4 & 5 \\
\hline
\end{tabular}

